Article

\title{
Sensitivity Analysis of Extreme Daily Rainfall Depth in Summer Season on Surface Air Temperature and Dew-Point Temperature
}

\author{
Inkyeong $\operatorname{Sim}^{1}\left(\mathbb{D}\right.$, Okjeong Lee $^{1}(\mathbb{D})$ and Sangdan Kim ${ }^{2, *(\mathbb{D})}$ \\ 1 Division of Earth Environmental System Science, Pukyong National University, Busan 48513, Korea; \\ ik4529@naver.com (I.S.); lover1804@nate.com (O.L.) \\ 2 Department of Environmental Engineering, Pukyong National University, Busan 48513, Korea \\ * Correspondence: skim@pknu.ac.kr; Tel.: +82-51-629-6529
}

Received: 15 March 2019; Accepted: 11 April 2019; Published: 13 April 2019

check for updates

\begin{abstract}
Looking at future data obtained from global climate models, it is expected that future extreme rainfall will increase in many parts of the world. The Clausius-Clapeyron equation provides a physical basis for understanding the sensitivity of rainfall in response to warming, but the relationship between rainfall and temperature is still uncertain. The purpose of this study is to analyze the sensitivity of extreme daily rainfall depth during the summer season (June-September) to climate change in Korea. The relationship between the observed extreme daily rainfall depth and the surface air temperature (SAT) and dew-point temperature (DPT), which were observed in the 60 sites of the Korea Meteorological Administration, were analyzed. The same analysis was also performed using future data provided in various climate models. In addition, the future trends of extreme rainfall, SAT, and DPT were analyzed using future data obtained from climate models, and the effects of increasing SAT and DPT on future extreme rainfall changes were investigated. Finally, it has been confirmed that using changes in SAT and DPT to look at changes in future extreme rainfall can give more consistent future projection results than using future rainfall data directly.
\end{abstract}

Keywords: climate change; dew-point temperature; extreme rainfall; surface air temperature

\section{Introduction}

As the rapid global warming has been taking place in recent years, the effects of climate change have become evident not only in Korea but globally [1,2], and the pace of change is increasing [3]. Local extreme storm events are frequent and the occurrence frequency and intensity of super typhoons are also increasing [4-6]. Bates et al. [7] reported that climate change can significantly change the occurrence frequency and intensity of extreme rainfall. Future climates obtained from various Global Climate Models (GCMs) and Regional Climate Models (RCMs) using IPCC (Intergovernmental Panel on Climate Change) AR5 climate change scenarios are predicted to generate more extreme rainfall more frequently [8]. Socioeconomic damages due to extreme rainfalls are also occurring continuously throughout the world $[9,10]$.

Extreme rainfall caused by climate change has become a global concern, and the importance of predicting and analyzing future extreme rainfall is increasing [11,12]. As climate change progresses, there has been a steady stream of analyses of the relationship between ambient temperature and extreme rainfall [13-15], and many related studies have been conducted accordingly. An analysis of the impacts of future climate change and a reasonable projection on extreme rainfall events are very important to minimize damage from extreme climates [16]. Particularly, understanding the changes of extreme rainfall is essential to prepare future society [17-19]. Anthropogenic greenhouse 
gas emissions have steadily increased since the late 20th century [20], and indeed there is a relationship between climate change and greenhouse gas emissions [20,21]. According to IPCC, rainfall patterns have been reported to change globally due to the increase in greenhouse gas emissions [22]. Many GCM simulations have shown that extreme climate events such as floods and droughts will increase globally $[22,23]$. Therefore, in order to reduce the damage caused by the predicted future disaster, it can be said that the most basic requirement is to examine the relationship between various weather variables and extreme climatic events [16,24].

Many studies have shown that climate change has a significant impact on rainfall intensity. In general, an increase in air temperature has been shown to cause extreme rainfall events in many parts of the world $[25,26]$. However, this hypothesis remains uncertain and does not imply equally affecting all regions of the world [27]. Temperature changes can directly affect the moisture content of the atmosphere governed by the Clausius-Clapeyron (C-C) equation, and in warmer climates the moisture content of the atmosphere increases and the intensity of rainfall increases at a similar rate $[28,29]$. In other words, according to the C-C relationship, the moisture content of the atmosphere increases exponentially with increasing temperature, while the moisture content of the atmosphere shows an increase rate of $6-7 \% / \mathrm{K}$ if other atmospheric conditions remain constant. When the relative humidity is constant, the humidity of the atmosphere increases at the same rate. Thus, the global mean temperature has risen by about $1^{\circ} \mathrm{C}$ over the past 100 years, and this results in more water vapor.

The impact of extreme events on climate change has been mainly driven by the operation of climate models with various climate change scenarios. Future extreme rainfall data obtained from climate models, however, are known to contain many uncertainties [30,31]. In other words, future projection results of surface air temperature (SAT) and dew-point temperature (DPT) are relatively consistent among the results of various climate models, while extreme rainfall cannot be considered a reliable result because very different future projection results are obtained depending on which climate model is used [32]. Uncertainties in future extreme rainfall in climate change scenario data were also discussed in Bae et al. [33] and Kim et al. [34].

O'Gorman [35] conducted a sensitivity analysis of the quantile of future daily rainfall obtained from climate models to analyze the sensitivity of extreme daily rainfall depth to climate change. Tramblay et al. [36] examined the impact of extreme rainfall on climate change using meteorological variables that reflect large-scale atmospheric cycles. Researches on the relationship between extreme rainfall and SAT have been actively conducted [16,37,38], and Ali and Mishra [39] and Wasko et al. [40] also examined the effect of SAT and DPT on extreme daily rainfall depth. In Korea, studies on the characteristics of future extreme rainfall using the results obtained from various climate models have been conducted (i.e., References [41-43]). However, studies on extreme rainfall using meteorological variables are lacking. Based on the results of researches on the relationship between extreme rainfall and SAT/DPT in Japan [13], Hong Kong [44] and China [45] in the last decades, performing similar analysis using data from the Korean region is a major motivation for this study. In addition, not only will the impact of the SAT or DPT on the extreme rainfall be explored, but how such impact analysis can reduce the many uncertainties in projecting the future extreme rainfall will also be investigated.

In this study, sensitivity analysis of extreme daily rainfall depth in summer is performed by selecting SAT and DPT among the observational meteorological variables of Korea Meteorological Administration (KMA). The relationship between extreme rainfall-SAT and extreme rainfall-DPT is analyzed for each observation site. The sensitivity of the extreme daily rainfall depth for each climate model combination is also analyzed using data obtained from various climate models in the same way. Based on the trends of future extreme rainfall, SAT, and DPT, projection results of future extreme rainfall are obtained. Compared with previous studies, the main novelty of this study may be the application of the annual exceedance rainfall depth. Most studies investigating the relationship between extreme rainfall and SAT/DPT have been of primary interest in finding cases that exceed the rates offered in the C-C relationship using all the different depths of rainfall [46-48]. In this study, first, the similar relationship between rainfall-SAT and rainfall-DPT for the quantile 0.95 is analyzed 
using quantile regression. After that, the constructed relationship of rainfall-SAT or rainfall-DPT is applied to analyze the effect of SAT/DPT on the annual exceedance rainfall depth. If the observed relationship between the annual exceedance rainfall depth and SAT/DPT is known and combined with future SAT/DPT information that yields a relatively consistent future projection result for this relationship, it is expected that a possible way to obtain projection results of a more consistent future extreme rainfall can be found.

\section{Materials and Methods}

\subsection{Study Area}

The Korean Peninsula extends south to north from 34 to $43^{\circ} \mathrm{N}$, showing a variety of weather patterns compared to small areas. It is located in the temperate zone of the mid-latitude and is characterized by distinct seasonal changes along with regional diversity. The characteristics of climate can be defined as continental climate in terms of temperature and monsoon climate in terms of precipitation or wind. The East Asian monsoon, which affects the summer rainfall in Korea, is closely related to the location and activity of the polar front formed at the boundary between East Asian continental air masses and marine air masses in the western Pacific [49]. Since more than half of the annual precipitation occurs during the summer in most of Korea, understanding and predicting summer rainfall for water resources management is a very important social issue [50].

Studies conducted in Korea have also reported that recent extreme rainfall changes are associated with climate change [51]. The main risk factors that cause serious damage to the Korean peninsula are extreme rainfall, and there is always the risk of secondary damage such as flooding or landslides. Due to the extreme rainfall event, serious natural disasters on the Korean Peninsula have been repeated almost every year. Therefore, reliable information on future climate change is essential to properly prepare future natural disasters in Korea. Since most natural disasters are associated with extreme rainfall events in Korea, there is an increasing social demand for studies on changes in extreme rainfall [52].

\subsection{Observed Data and Sensitivity Analysis}

In this study, daily meteorological data of 60 ASOS (Automated Synoptic Observing System) monitoring sites operated by KMA were collected and analyzed for daily rainfall depth, daily SAT, and daily DPT from 1973 to 2017. The selection criteria of the observation site was the site where the data measurement started before 1 January 1973, and sites with more than $10 \%$ of the missing data for any period during the period of 1973-2017 were excluded. Missing data was supplemented by observed data from surrounding sites.

The daily ASOS meteorological data was derived from the hourly observations and are available on the KMA website [53]. To analyze the sensitivity of extreme daily rainfall depth during summer, data from June to September were extracted and used for analysis. The data observed in KMA were used as they were except for the correction of missing values of rainfall, SAT, and DPT data. No special analysis was done on outliers, trends, homogeneity, and independence of observed data.

In this study, it was analyzed how much the daily rainfall depth would be affected when SAT and DPT increase. Since only SAT/DPT observed on the day when daily rainfall was observed does not affect daily rainfall, the analysis was carried out with the SAT/DPT up to the previous 7 days (t-day for $t=0,1, \ldots, 7)$ including the day on which the daily rainfall was observed. Sensitivity analysis was performed in two ways: 1) quantile regression analysis of daily rainfall using $95 \%$ quantile and 2) linear regression analysis of annual exceedance daily rainfall depth.

Quantile regression analysis estimates the linear model using the conditional $\tau$-quantile rather than the mean of dependent variables. Compared to general linear regression, it has the advantage of providing estimates that are not sensitive to outliers or asymmetric distributions. Since Korea's rainfall data show a very large variance and a highly distorted distribution, quantile regression analysis is 
considered to be appropriate for examining the sensitivity of extreme daily rainfall depth. A daily rainfall depth of $0.1 \mathrm{~mm}$ or more was applied to the analysis and a regression slope of $95 \%$ extreme daily rainfall depth corresponding to SAT and DPT was estimated. For reference, the quantile regression equation for a given quantile $\tau$ ( 0.95 in this study) in the quantile regression analysis is as follows [54]:

$$
\ln R_{\tau}=a+b T,
$$

where $R_{\tau}$ is the daily rainfall depth and $T$ is the SAT or DPT. The same regression form as that applied by Lepore et al. [54] was also applied in this study for the purpose of explicitly exploring the relationship between rainfall-SAT and rainfall-DPT. To investigate the percent increase or decrease in daily rainfall when the SAT or DPT increases by $1 \mathrm{~K}$, Equation (2) is constructed using Equation (1).

$$
\mathrm{d} R_{\tau}(\%) / K=100\left(e^{b}-1\right),
$$

Meanwhile, the relationship between extreme daily rainfall depth and SAT or DPT was analyzed using the annual exceedance daily rainfall depth in summer. In extracting the annual exceedance time series, the rainfall event with a duration of more than 2 days was regarded as one rainfall event, and only the largest value among consecutive daily rainfall depths was selected. The number of annual exceedance time series is equal to the number of observation years of data. As with the quantile regression analysis, the sensitivity of the annual exceedance daily rainfall depth for the SAT/DPT was analyzed by extracting the SAT/DPT for the preceding 7 days as well as the SAT/DPT for the same day when the annual exceedance daily rainfall depth occurred.

The regression equations for the annual exceedance daily rainfall depth corresponding to the SAT and DPT were constructed in the same form as the quantile regression as follows:

$$
\ln E_{\tau}=a+b T,
$$

where $E_{\tau}$ is the annual exceedance daily rainfall depth and $T$ is the SAT or DPT. The sensitivities that indicate how many percent increase or decrease in the annual exceedance daily rainfall depth when the SAT or DPT increases by $1{ }^{\circ} \mathrm{C}$ are constructed as Equation (4) using Equation (3).

$$
\mathrm{d} E_{\tau}(\%) / K=100\left(e^{b}-1\right),
$$

\subsection{Future Climate Data and Trend Analysis}

Because of the low spatial resolution of GCMs, the peninsula area, which has a small land area like the Korean peninsula and is highly affected by the ocean, has difficulties in projecting future climate using GCMs. It is therefore reasonable to look at the future climate using the results from RCMs that dynamically down-scale the results of GCMs. This study used dynamically down-scaled data (KOR-11) with $12.5-\mathrm{km}$ horizontal resolution in East Asia including the Korean peninsula. Representative Concentration Pathways (RCP) 4.5 and 8.5 were applied as future climate change scenarios in KOR-11, and two GCMs including MPI-ESM-LR (Max Plank Institute Earth System Model-Low Resolution, ML) and HadGEM2-AO (Hadly Center Global Environmental Model version 2 coupled with the Atmosphere-Ocean, H2) and four RCMs (MM5, RegCM4, RSM, WRF) were used. Therefore, KOR-11 has produced a total of 16 future ensembles. Table 1 summarizes the future climate information used in this study. 
Table 1. Information of future climate models data.

\begin{tabular}{|c|c|c|c|c|c|}
\hline GCMs & RCMs & Scenarios & $\begin{array}{c}\text { Spatial } \\
\text { Resolution }\end{array}$ & $\begin{array}{l}\text { Temporal } \\
\text { Resolution }\end{array}$ & $\begin{array}{l}\text { Temporal } \\
\text { Scale }\end{array}$ \\
\hline \multirow{4}{*}{$\begin{array}{l}\text { MPI-ESM-LR } \\
\text { (LR) }\end{array}$} & MM5 & \multirow{8}{*}{$\begin{array}{l}\mathrm{RCP} 4.5 \\
\mathrm{RCP} 8.5\end{array}$} & \multirow{8}{*}{$12.5-\mathrm{km}$} & & \multirow{8}{*}{$\begin{array}{c}\text { Present: } \\
\text { 1981 2010 } \\
\text { Future: } \\
\text { 2021 2050 }\end{array}$} \\
\hline & WRF & & & $3-h$ & \\
\hline & RegCM4 & & & (365-Day in 1 -year) & \\
\hline & RSM & & & & \\
\hline \multirow{4}{*}{$\begin{array}{l}\text { HadGEM2-AO } \\
\text { (H2) }\end{array}$} & MM5 & & & & \\
\hline & WRF & & & & \\
\hline & RegCM4 & & & \multirow{2}{*}{$\begin{array}{c}3-\mathrm{h} \\
\text { (360-Day in 1-year) }\end{array}$} & \\
\hline & RSM & & & & \\
\hline
\end{tabular}

Notes: Global Climate Models (GCMs); Regional Climate Models (RCMs); Representative Concentration Pathways (RCP).

Compared to GCMs, RCMs simulate local climate characteristics in more detail and more plausibly, but still have significant bias [55]. Therefore, in order to use the data obtained from RCMs, it is necessary to correct the bias between the observed data and the corresponding data obtained from the model. Numerous bias-correction methods have been developed. In this study, Quantile-Mapping (QM) technique, which has been used in many studies and can be applied relatively easily, was used.

The bias correction using QM can be performed using Equations (8) and (9) as follows [34,56-64]:

$$
\begin{aligned}
& X_{p}^{\prime}=F_{o}^{-1}\left(F_{p}\left(X_{p}\right)\right), \\
& X_{f}^{\prime}=F_{o}^{-1}\left(F_{p}\left(X_{f}\right)\right),
\end{aligned}
$$

In Equations (5) and (6), $X_{p}$ is the present climate simulation data, $X_{p}^{\prime}$ is the corrected present climate simulation data, $X_{f}$ is the future climate simulation data, and $X_{f}^{\prime}$ is the corrected future climate simulation data. $F_{p}$ is the Cumulative Distribution Function (CDF) of the present climate simulation data and $F_{o}^{-1}$ is the Inverse Cumulative Distribution Function (ICDF) of the corresponding observed data. First, after non-exceeding probabilities of present climate simulations are obtained using $F_{p}$, they are assigned to $F_{o}^{-1}$ to obtain bias-corrected present climate simulations (see Equation (5)). Then the same procedure is applied to the future climate simulations to correct the bias (see Equation (6)). The CDF and ICDF required to perform the QM were determined by the non-parametric method using the kernel smoothing technique.

A trend analysis of SAT and DPT was conducted on 60 sites operated by KMA. First, the present and future daily SAT and DPT time series produced by 16 ensembles of RCP-GCM-RCM combinations after the bias-correction process for each site were averaged yearly during the summer season to calculate yearly SAT and DPT. SAT and DPT trends were analyzed using Equations (7) and (8) from the calculated yearly SAT and DPT time series [65].

$$
\begin{aligned}
& \Delta S A T_{Y}=\alpha_{S} \cdot(Y-2010)+\frac{1}{2} \cdot \beta_{s} \cdot(Y-2010)^{2}, \\
& \Delta D P T_{Y}=\alpha_{d} \cdot(Y-2010)+\frac{1}{2} \cdot \beta_{d} \cdot(Y-2010)^{2},
\end{aligned}
$$

where $\triangle S A T_{Y}$ or $\triangle D P T_{Y}$ is the annual mean SAT or DPT of the future year $Y$ minus the average of the yearly SAT or DPT for the present period (1981-2010), and linear trend coefficients $\left(\alpha_{s} \& \alpha_{d}\right)$ and trend acceleration coefficients $\left(\beta_{s} \& \beta_{d}\right)$ were estimated using regression analysis. In Equations (7) and (8), 2010 represents the last year of the present period. 
For the annual exceedance daily rainfall time series, it is not appropriate to use the same method as the trend analysis of the SAT and DPT due to the irregular nature of the rainfall time series. Instead, the rate of change of the average of the annual exceedance time series of the future period to the average of the annual exceedance time series of the present period was calculated using Equation (9) as follows:

$$
R_{C R}=\frac{E\left[R_{F}\right]-E\left[R_{P}\right]}{E\left[R_{P}\right]},
$$

where $R_{C R}$ is the rate of change over the mean of the annual exceedance time series, $E\left[R_{F}\right]$ is the average of the annual exceedance time series of the future period, and $E\left[R_{P}\right]$ is the average of the annual exceedance time series of the present period.

\section{Results and Discussion}

\subsection{Sensitivity Analysis of Observed Data}

Figure 1 shows the sensitivity of daily rainfall to SAT and DPT in Busan site using quantile regression.

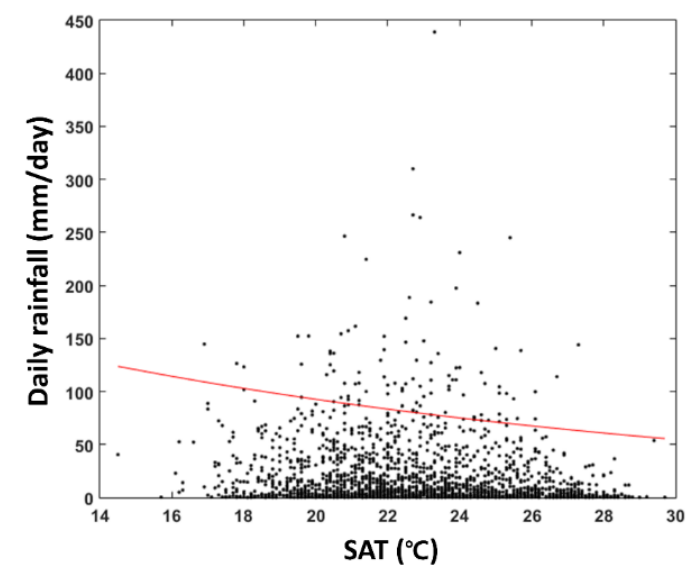

(a) Rainfall-SAT

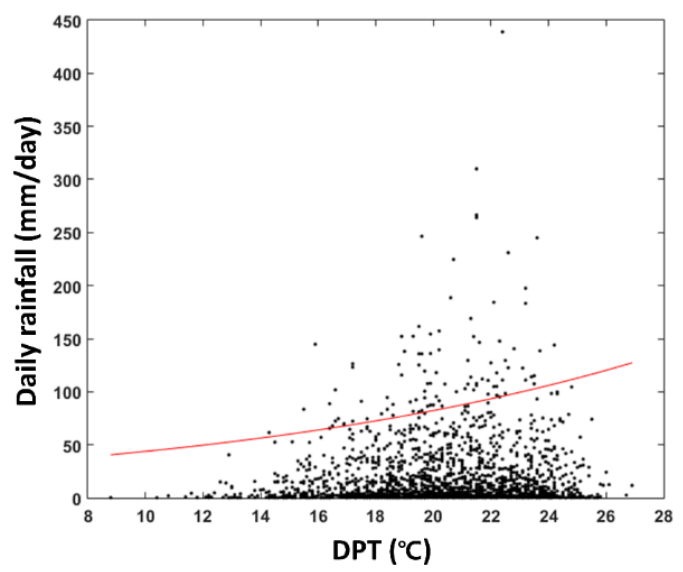

(b) Rainfall-DPT

Figure 1. Sensitivity of $95 \%$ daily rainfall depth at Busan site.

As can be seen in Figure 1, daily rainfall increases when DPT increases by $1 \mathrm{~K}$, while daily rainfall decreases when SAT increases by $1 \mathrm{~K}$. Using the same method, the relationship between daily rainfall and SAT/DPT was analyzed at all sites (see Figures 2 and 3). Note that almost all sites had significant evidence that the p-value for the predictor in the quantile regression was less than 0.05. In Figures 2 and 3 , "๑" means positive sensitivity, " $\mathbf{\wedge}$ " means negative sensitivity, and the larger the absolute value of sensitivity, the darker the color. 


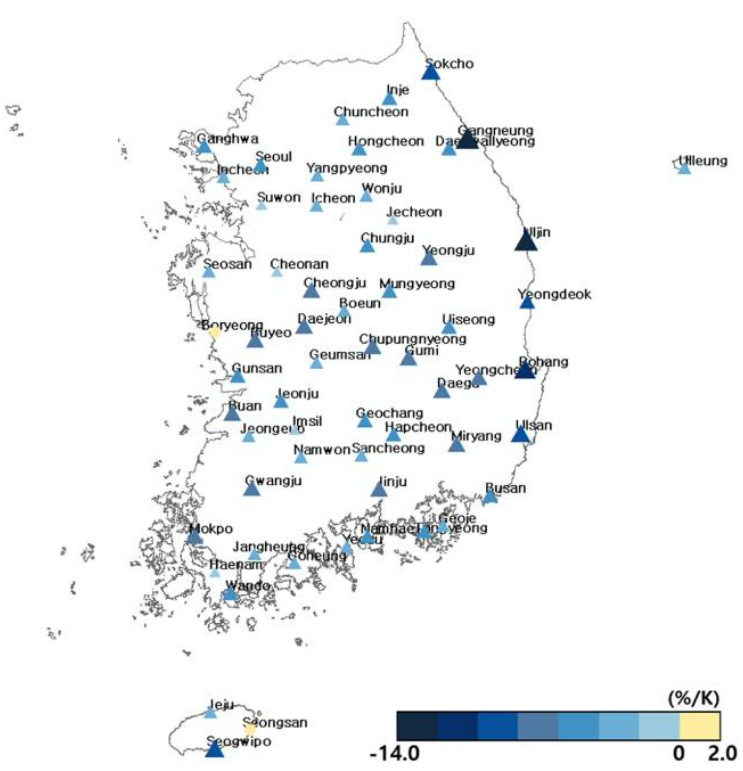

(a) SAT on the rainy day

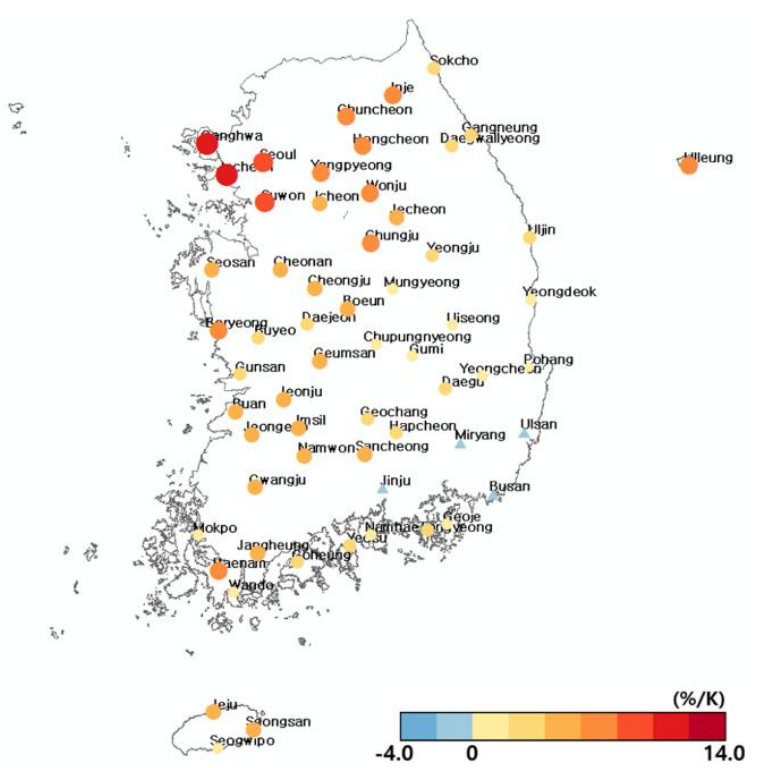

(b) SAT in t-day before rain

Figure 2. Sensitivity of $95 \%$ daily rainfall depth to SAT in all sites.

Figure 2a shows the results of daily rainfall and SAT on the day of rainfall, and Figure $2 b$ shows the highest sensitivity among daily rainfall and SAT at $t$-day (for $t=0,1, \ldots, 7)$. The case of Figure $2 b$ can be explained again as follows: First, the $\mathrm{d} R_{\tau}(\%) / K$ of Equation (2) can be estimated using the daily rainfall and the SAT of the rainfall day. In the same way, the $\mathrm{d} R_{\tau}(\%) / K$ of Equation (2) is estimated using the daily rainfall and SAT 1-day before rain. Similarly, the $\mathrm{d} R_{\tau}(\%) / K$ is estimated using SAT 2-day before, 3-day before, ..., 7-day before rain. The highest value among the eight $\mathrm{d} R_{\tau}(\%) / K$ values calculated is defined as the highest sensitivity of the site, which is shown in Figure $2 \mathrm{~b}$. As mentioned above, since the $\mathrm{p}$-value for the predictor in the quantile regression was less than 0.05 in almost all sites, the coefficient $b$ in Equation (2) was thought to be statistically significant.

Figure 3 shows the relationship between daily rainfall and DPT. Figure 3a shows the sensitivity using DPT at 0-day. Figure $3 \mathrm{~b}$ shows the results with the highest sensitivity among daily rainfall and DPT at $t$-day (for $t=0,1, \ldots, 7$ ). While sensitivity analysis of daily rainfall for SAT showed negative sensitivity at most sites, the relationship between daily rainfall and DPT showed positive sensitivity. Sensitivity ranged from -1.04 to $12.74 \% / \mathrm{K}$ and the national average was $5.20 \% / \mathrm{K}$. That is, the daily rainfall was increased when DPT increased by $1 \mathrm{~K}$ in most observation sites except five sites. Five observational sites with negative sensitivity were Daegwallyeong site and Chupungnyeong site in mountain area and three coastal sites. In the northern region, the positive sensitivity was relatively clear. The sensitivity of DPT at $\mathrm{t}$-day (for $\mathrm{t}=0,1, \ldots, 7$ ) ranged from -0.26 to $12.74 \% / \mathrm{K}$ and the national average was $5.80 \% / \mathrm{K}$. This means that the sensitivity increases in the positive direction compared to the DPT at 0-day. In most sites, DPT at 0-day or DPT at 1-day showed the greatest sensitivity. It has also been found that the sites with negative sensitivity when applying DPT at 0-day are converted to positive sensitivity by applying DPT at $t$-day (for $t=0,1, \ldots, 7$ ). 


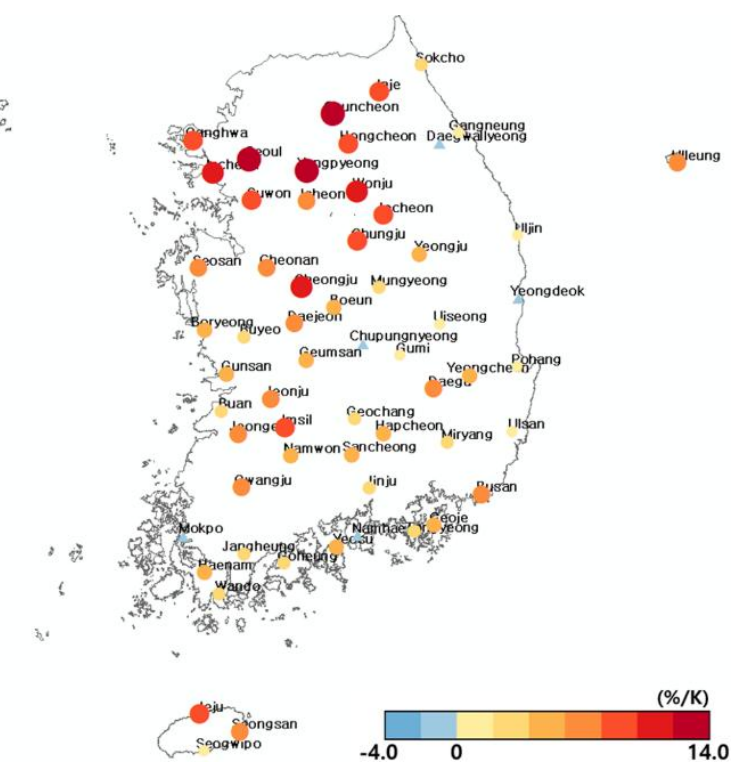

(a) DPT on the rainy day

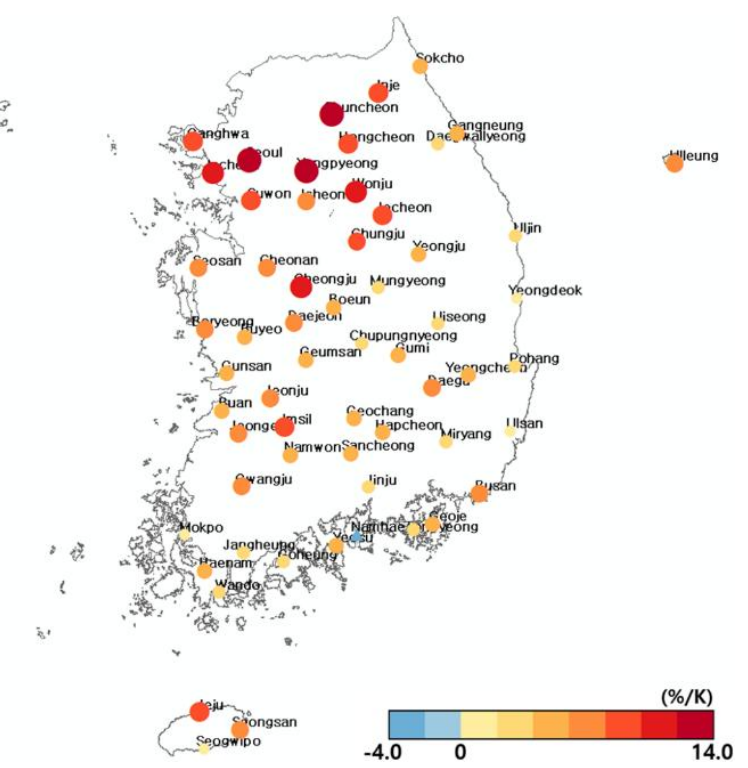

(b) DPT in t-day before rain

Figure 3. Sensitivity of $95 \%$ daily rainfall depth to DPT in all sites.

In summary, the daily rainfall sensitivity to DPT was positive (i.e., the daily rainfall also increased when DPT was increased), and the daily rainfall sensitivity to SAT was negative (i.e., daily rainfall decreases with increasing SAT). However, when SAT/DPT at $\mathrm{t}$-day (for $\mathrm{t}=0,1, \ldots, 7$ ) was applied, it was found that daily rainfall showed positive sensitivity for both meteorological variables. Figure 4 shows the distribution of $\mathrm{t}$-day which shows the highest sensitivity as a result of SAT and DPT analysis.

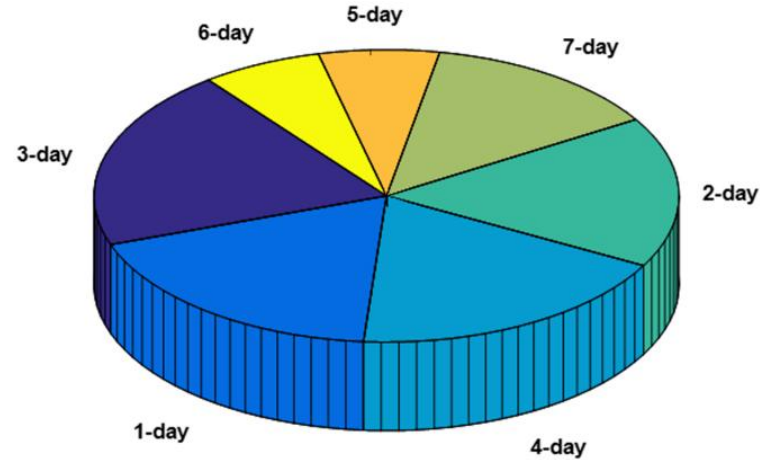

(a) Rainfall-SAT

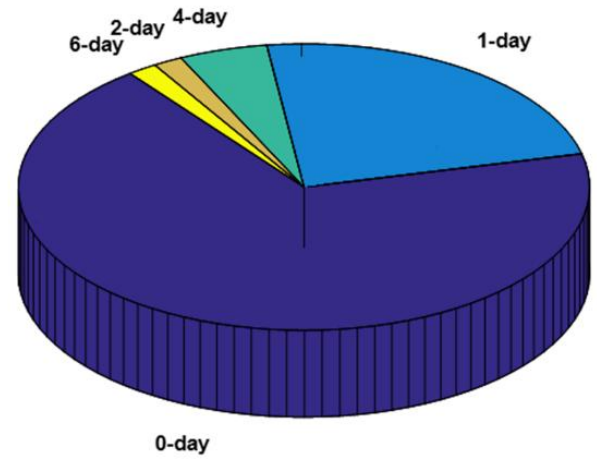

(b) Rainfall-DPT

Figure 4. Distribution of preceding-day showing maximum sensitivity in 95\% daily rainfall depth.

Figure 4a shows that SAT at 3-day has the largest number of sites with the highest sensitivity to daily rainfall. SAT at 1-day, 2-day, and 4-day also had the greatest sensitivity. However, there was no site with the highest sensitivity at SAT at 0-day. It is analyzed that Korea belongs to a marine monsoon climate. In other words, most of the rainfall in Korea occurs in the summer, and when the storm event affected by the ocean occurs, it causes a temporary SAT cooling effect. Therefore, it can be deduced that there is a negative correlation between daily rainfall and SAT on the day of rainfall. This means that SAT may not be sufficient to understand the changes in rainfall extremes over Korea in response to global warming. On the other hand, Figure $4 \mathrm{~b}$ shows that DPT at 0 -day is the most sensitive to daily rainfall. Since the relationship between rainfall and humidity can be good information for analyzing changes in rainfall in warmer climate conditions, so the results shown in Figure $4 \mathrm{~b}$ were thought to be good evidence that the use of DPT as a measure of humidity was valid. 
From the above results, it can be seen that the regression slope between the extreme rainfall and the daily mean SAT was negative in almost all sites. The negative sensitivity between the extreme rainfall and the daily mean SAT is mainly due to the surface temperature drop caused by rainfall event occurrences. However, it was found that almost all the sites showed positive sensitivity when the SAT was used 1-day to 3-day before the rain, rather than on the rainy day. The negative correlation between extreme rainfall and the daily mean SAT in most parts of Korea provides some important insights. Due to the negative correlation between Korea's extreme rainfall and the daily mean SAT, the SAT may be treated as unnecessary on the way to understanding the extreme rainfall response under global warming. However, such a negative correlation in the monsoon region is mainly a reflection of the surface temperature response to rainfall rather than the $\mathrm{C}-\mathrm{C}$ relationship. Thus, a firm relationship between the extreme rainfall and the daily mean SAT could be obtained using the pre-rain SAT, and it would be possible to find ways to understand the response of the extreme rainfall due to climate change.

The relationship between extreme rainfall and humidity can be a good indicator of the extreme rainfall in warming climates, so DPT was used as a measure of absolute humidity in this study. The regression slope obtained using quantile regression was estimated to be greater than the C-C rate $(7 \%)$ in many sites in Korea. The negative correlation between Korea's extreme rainfall and the SAT mentioned above may not be sufficient to understand the extreme rainfall response to climate change. However, the relationship between extreme rainfall and DPT was relatively robust and easily identifiable, which may help to understand changes in extreme rainfall under warming climate. These results also show that the sensitivity assessment for SAT may not be the only or most optimal way to investigate Korea's extreme rainfall under warming climate.

Figure 5 shows the sensitivity of annual exceedance daily rainfall depth to the SAT and DPT of Busan site using linear regression.

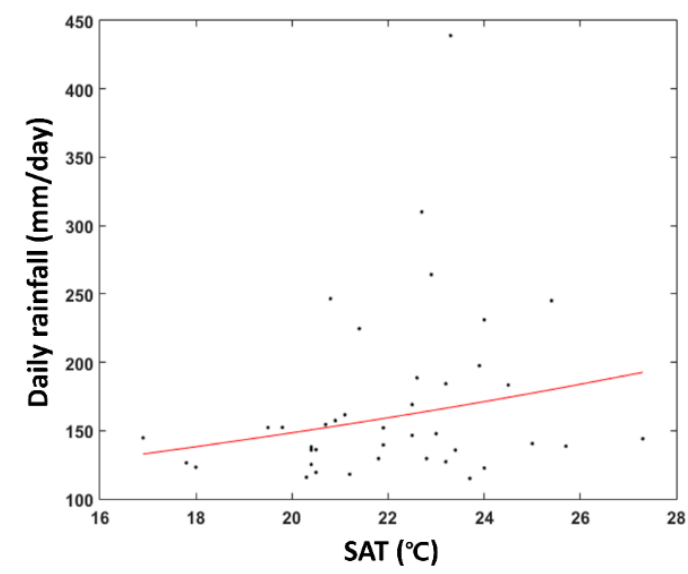

(a) Rainfall-SAT

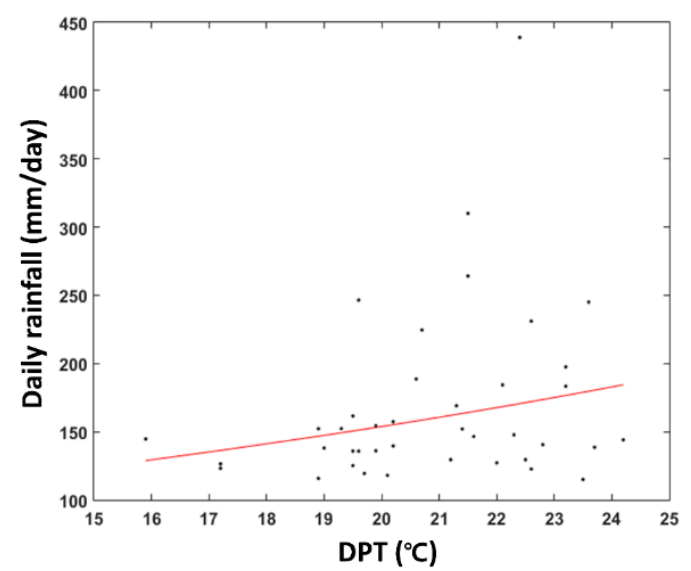

(b) Rainfall-DPT

Figure 5. Sensitivity of annual exceedance daily rainfall depth at Busan site.

In the quantile regression analysis, the relationship between daily rainfall and SAT was negative (see Figure 1). However, both the SAT and DPT showed positive sensitivity for the annual exceedance daily rainfall depth. In this way, the relationship between annual exceedance daily rainfall depth and SAT/DPT for all sites is analyzed and shown in Figures 6 and 7 . Note that the range of $R^{2}$ statistic in the linear regression analysis of each site ranged from 0.03 to 0.25 . Since the coefficient of determination itself was not large, the reliability of the linear regression analysis was found to be low. However, as shown in Figures $6 \mathrm{~b}$ and $7 \mathrm{~b}$, showing the positive sensitivity at almost all sites, and with the results of quantile regression, the relationship between SAT/DPT and the annual exceedance daily rainfall depth was considered to have a certain positive correlation if only the lead time of the SAT/DPT was properly set. 


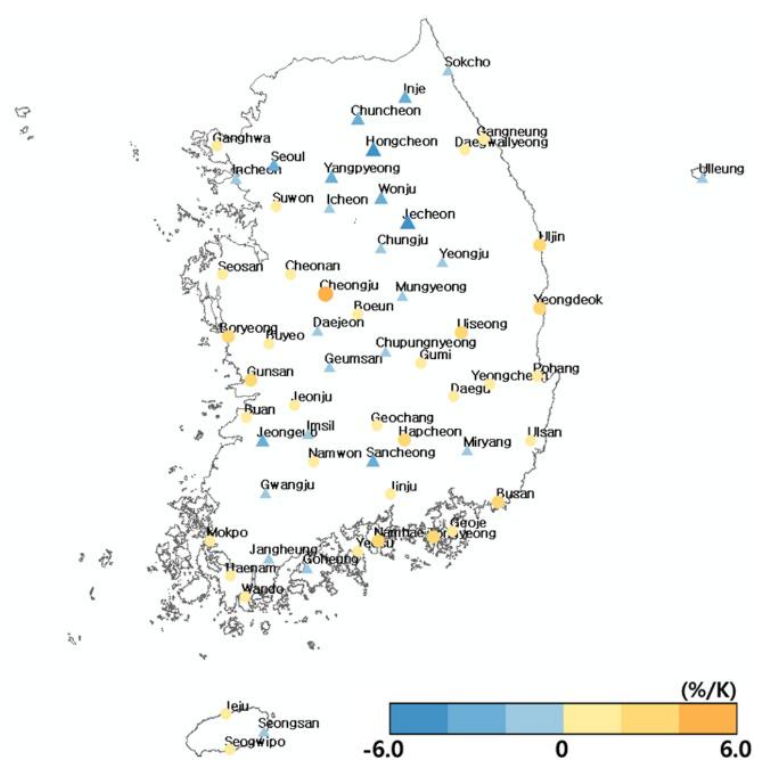

(a) SAT on the rainy day

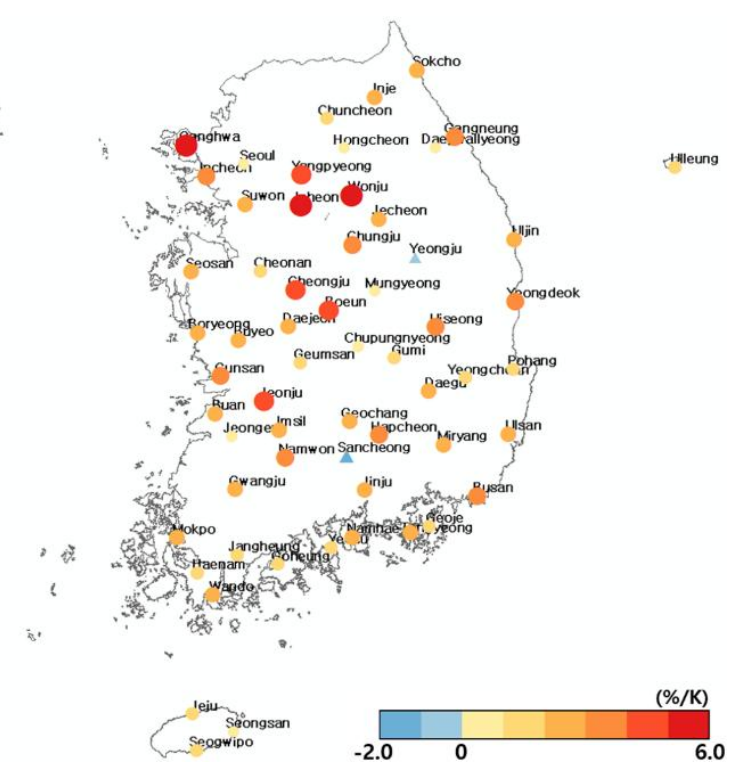

(b) SAT in t-day before rain

Figure 6. Sensitivity of annual exceedance daily rainfall depth to SAT in all sites.

Figure $6 \mathrm{a}$ shows the result obtained by applying SAT at 0 -day. Figure $6 \mathrm{~b}$ shows the result obtained by selecting $\mathrm{t}$-day with the highest sensitivity using SAT at $\mathrm{t}$-day (for $\mathrm{t}=0,1, \ldots, 7$ ). The sensitivity range of the $95 \%$ daily rainfall for the SAT $1 \mathrm{~K}$ rise was $-13.20 \sim 0.86 \% / \mathrm{K}$, while the sensitivity range for the annual exceedance time series was $-5.43 \sim 4.09 \% / \mathrm{K}$. This means that the annual exceedance time series is more sensitive to the SAT rise than the $95 \%$ daily rainfall and the sensitivity difference between sites is relatively small. In the case of $95 \%$ daily rainfall, all sites except two sites showed negative sensitivity, while in case of annual exceedance time series, both positive and negative sensitivities were mixed. Especially, the coastal area showed relatively positive sensitivity. On the other hand, the sensitivity range for SAT at $\mathrm{t}$-day (for $\mathrm{t}=0,1, \ldots, 7$ ) was $-1.69 \sim 5.99 \% / \mathrm{K}$, and the national average was $2.37 \% / \mathrm{K}$. For the reference, the sites with the highest sensitivity when applying SAT at 4-day were the most, followed by SAT at 7-day. Sensitivity to SAT at 0-day was mixed with positive and negative sensitivities, but sensitivity to SAT at $\mathrm{t}$-day (for $\mathrm{t}=0,1, \ldots, 7$ ) was found to be positive in most sites.

Figure $7 \mathrm{a}$ shows the result of applying the DPT of the day when the annual exceedance daily rainfall depth occurred, and Figure $7 \mathrm{~b}$ shows the result of selecting the highest sensitivity by applying DPT at $\mathrm{t}$-day (for $\mathrm{t}=0,1, \ldots, 7$ ). The sensitivity range of $95 \%$ daily rainfall was $-1.04 \sim 12.74 \% / \mathrm{K}$, while the sensitivity range of annual exceedance time series was $-4.81 \sim 4.41 \% / \mathrm{K}$. The national average was $0.31 \% / \mathrm{K}$. That is, the sensitivity of the annual exceedance daily rainfall depth is smaller than the sensitivity of the $95 \%$ daily rainfall, but the sensitivity difference between the sites is relatively small. In addition, unlike the analysis of $95 \%$ daily rainfall, the sensitivity of the annual exceedance time series was mixed with positive sensitivity sites and negative sensitivity sites, and in the northern region, negative sensitivity was observed. On the other hand, the sensitivity range for DPT at $t$-day (for $\mathrm{t}=0,1, \ldots, 7$ ) was $-0.76 \sim 4.87 \% / \mathrm{K}$, and the national average was $2.02 \% / \mathrm{K}$. Most sites showed positive sensitivity. For the reference, the sites with the highest sensitivity when applying DPT at 1-day were the most, followed by DPT at 0-day. 


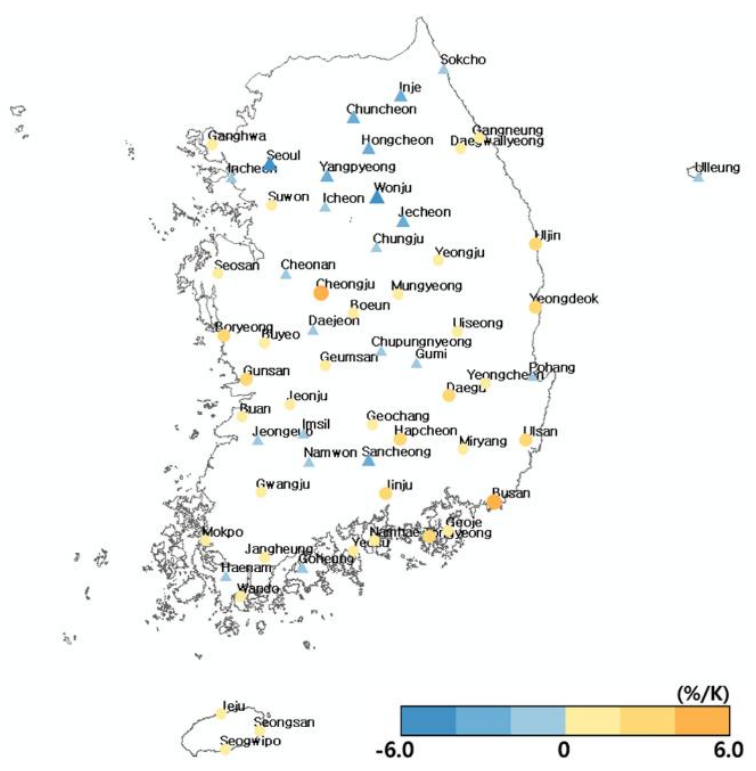

(a) DPT on the rainy day

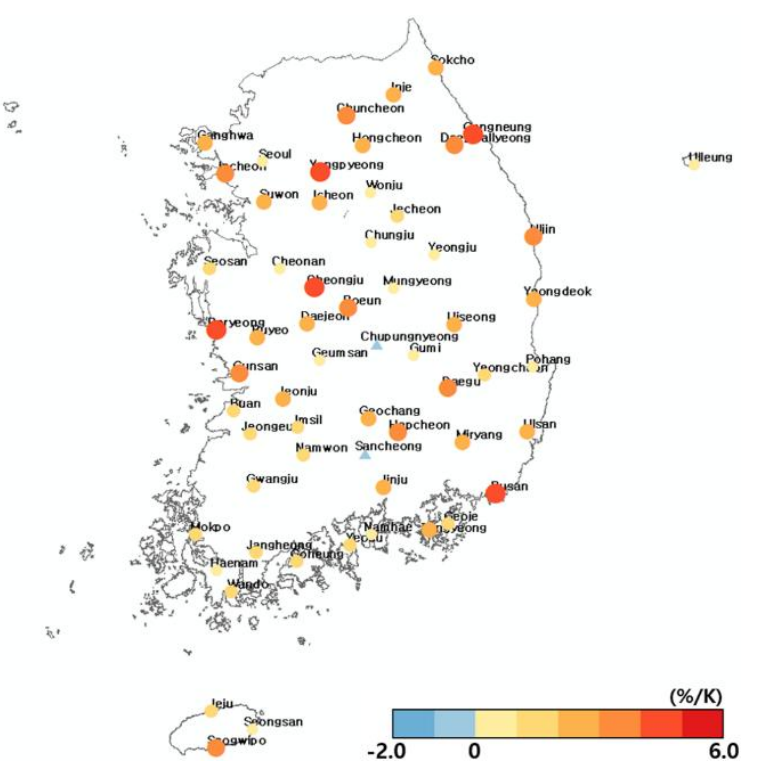

(b) DPT in t-day before rain

Figure 7. Sensitivity of annual exceedance daily rainfall depth to DPT in all sites.

The analysis of the sensitivity of the annual exceedance daily rainfall depth for the SAT and the DPT showed that both the positive sensitivity sites and the negative sensitivity sites were mixed when the SAT/DPT at 0-day was applied. However, SAT/DPT at $\mathrm{t}$-day (for $\mathrm{t}=0,1, \ldots, 7$ ) showed positive sensitivity in most sites. Figure 8 shows the distribution of $t$-days giving the highest sensitivity at each site.

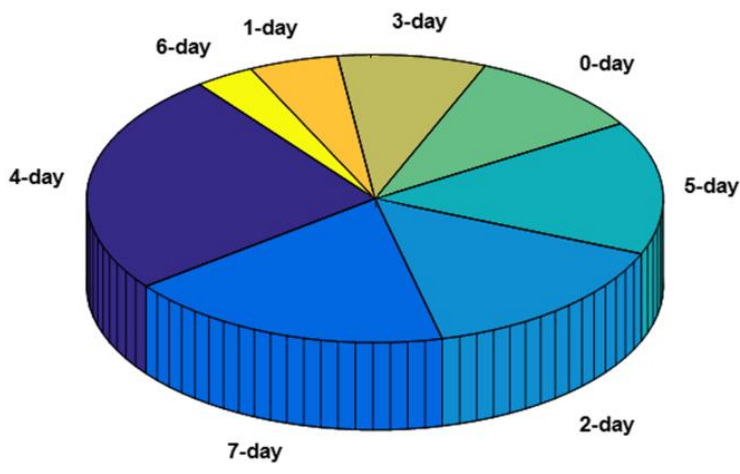

(a) Rainfall-SAT

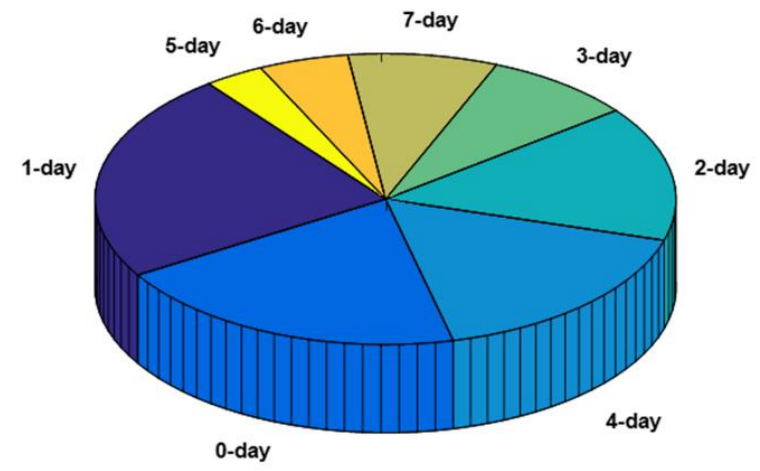

(b) Rainfall-DPT

Figure 8. Distribution of preceding-day showing maximum sensitivity in annual exceedance daily rainfall depth.

Figure 8a shows the relationship between SAT and annual exceedance daily rainfall depth. The SATs at $\mathrm{t}=4$-day and $\mathrm{t}=7$-day showed the greatest sensitivity. Figure $8 \mathrm{~b}$ shows the relationship between DPT and annual exceedance daily rainfall depth. Most sites showed the greatest sensitivity at $\mathrm{t}=1$-day. As shown in the previous $95 \%$ daily rainfall analysis, the SAT preceding days are estimated to be relatively longer than the preceding days of the DPT due to the surface cooling effect on the day of rainfall in summer.

As shown in the above results, the relationship between the annual exceedance daily rainfall depth-SAT or the annual exceedance daily rainfall depth-DPT was not clearer than that in the quantile regression. Although the number of data used in the analysis may be one of several causes, it would be reasonable to say that the annual exceedance daily rainfall depth and SAT/DPT cannot be easily expressed in the form of such simple formulas. Regardless of the statistical significance of the regression analysis, the number of data used, and so on, it should be noted here that the relationship between the 
annual exceedance daily rainfall depth-SAT or the annual exceedance daily rainfall depth-DPT was positively correlated in most of the analyzed sites. A rough estimate of $2 \% / \mathrm{K}$ can be obtained, which would be a reasonable estimate of extreme rainfall response under global warming. Some previous studies showed that the rate of change of extreme rainfall due to climate change was more than $50 \%$. Apart from the rationality of techniques applied in such studies, the value of such a rate of change cannot be accepted as realistic, so it does not help at all in establishing a climate change adaptation plan in practice. The $2 \%$ increase in extreme rainfall over the SAT or DPT $1{ }^{\circ} \mathrm{C}$ increase is expected to play an important role in presenting the rate of change of future extreme rainfall considering the various climate change scenarios at a level acceptable to reality.

\subsection{Trend Analysis of Future Projection Data}

Figure 9 shows trend curves derived using Equations (7) and (8) and future yearly SAT ensemble at Busan site, and Figure 10 shows the results for DPT. In order to examine the trend of the data, the non-parametric trend analysis of all data was performed using the Mann-Kendall test. It was found that there was a tendency at the 0.05 significance level in all future yearly SAT and future yearly DPT derived from future climate models. All p-values in each test were found to be less than 0.05 . In Figures 9 and 10, "** is the observation data, " $\bigcirc$ " is the yearly SAT or yearly DPT in present and future climate conditions obtained from climate models. The solid line is the trend line obtained using Equations (7) and (8). The horizontal axis is from 1980 to 2050, and the vertical axis is yearly SAT or yearly DPT in Celsius degree. In both SAT and DPT, the acceleration component of the trend was not clearly seen, but it was found that the linear trend component appeared clearly.
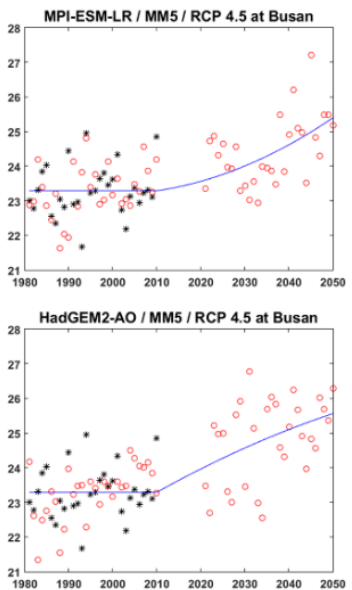

MPI-ESM-LR / MM5 / RCP 8.5 at Busan

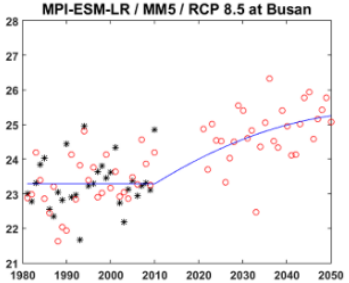

HadGEM2-AO / MM5 / RCP 8.5 at Busan

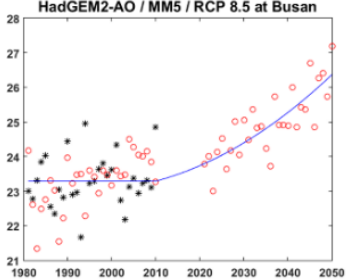

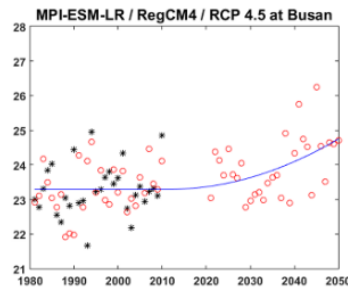
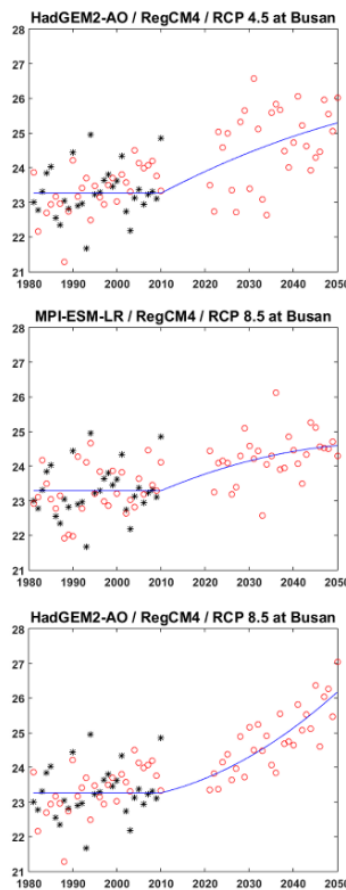
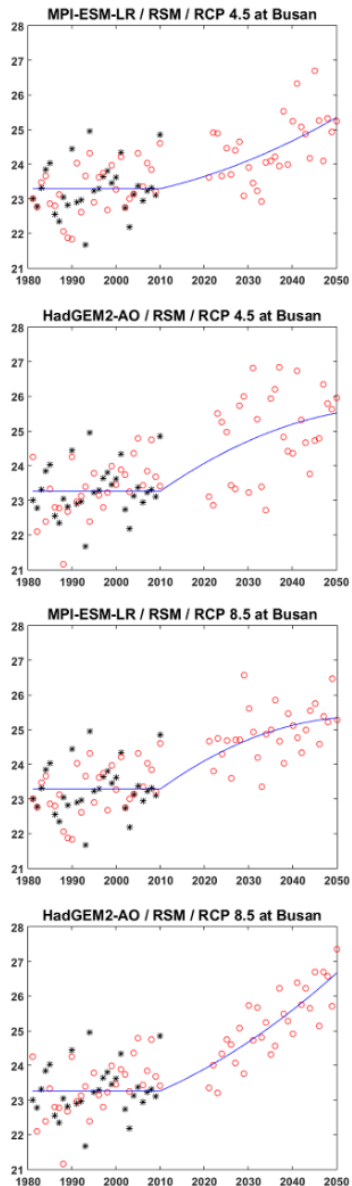
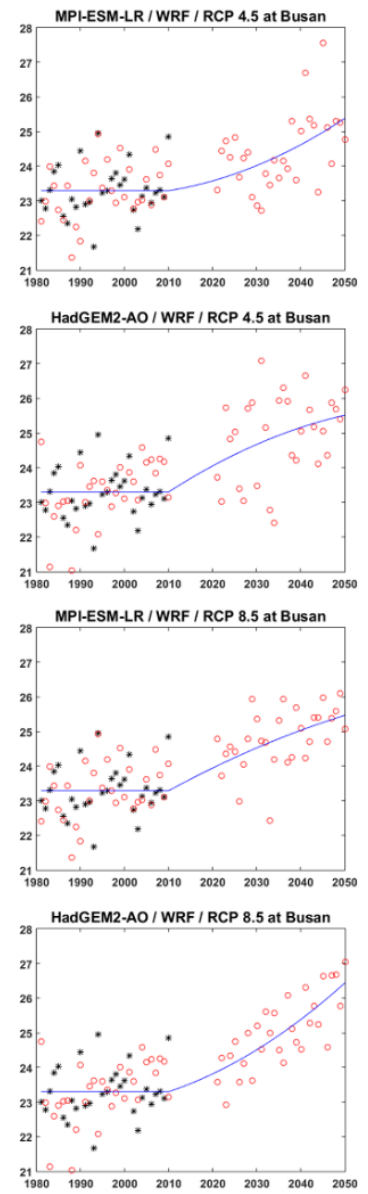

Figure 9. Yearly SAT time series at Busan site. 

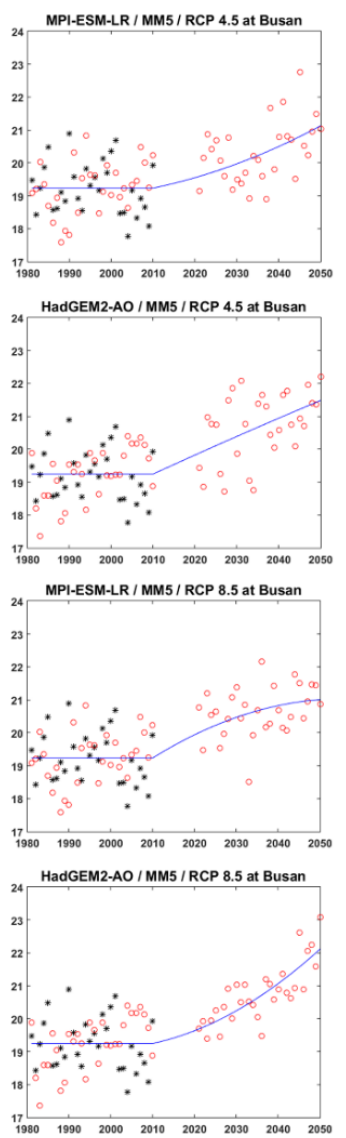
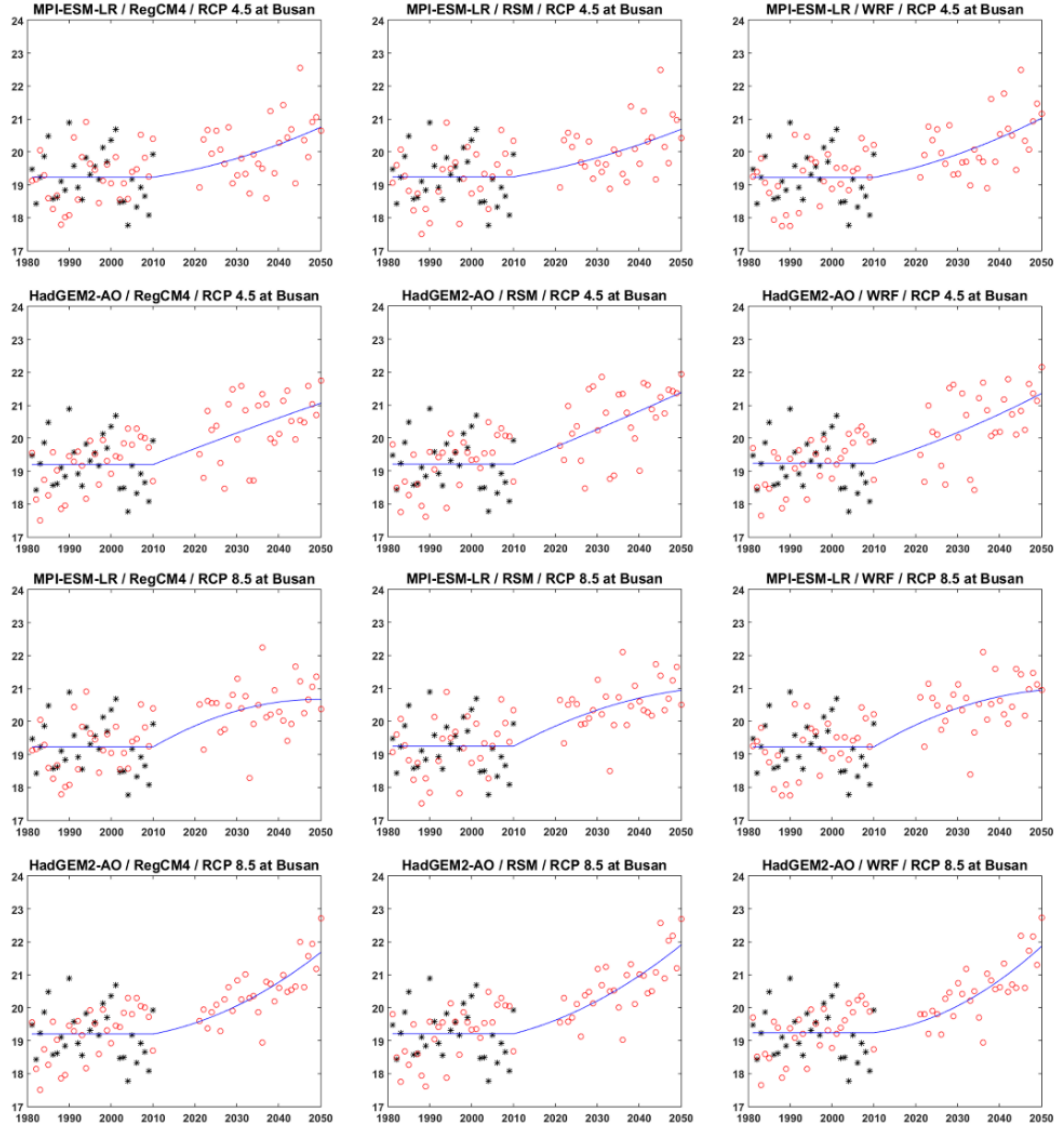

Figure 10. Yearly DPT time series at Busan site.

Figure 11 shows the rate of change of SAT and DPT in the future versus present using trend analysis results. For all future ensembles used, the rate of change for both SAT and DPT increased, and SAT and DPT growth rates were higher in RCP 8.5 scenario than in RCP 4.5 scenario. On the other hand, it was found that the deviation between the 16 future ensembles is not large in view of the future change rate compared to the present.

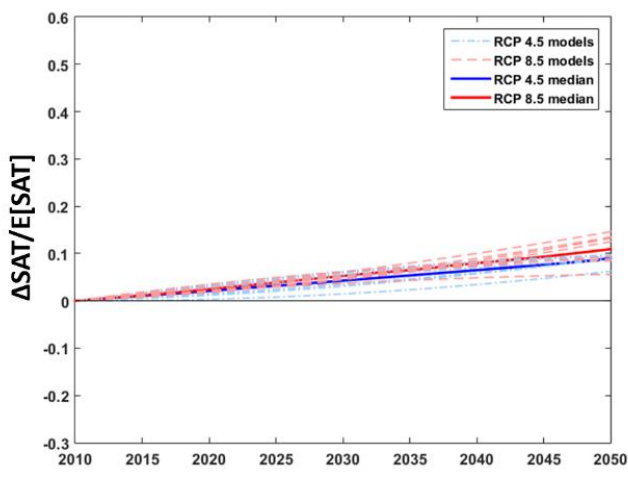

(a)

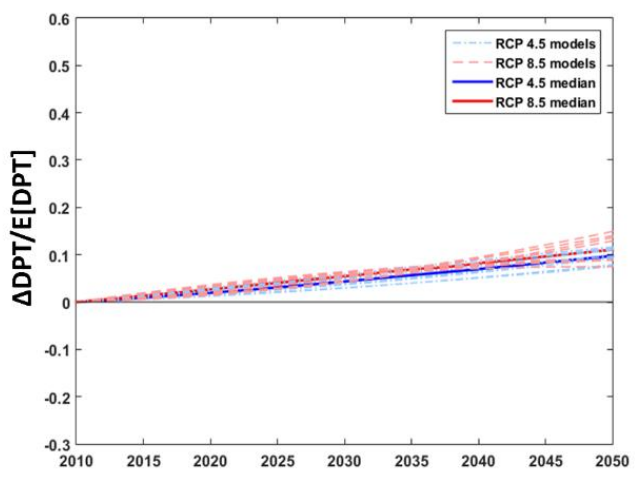

(b)

Figure 11. Trend analysis of SAT and DPT at Busan site.

Figure 12 shows the ensemble of present and future annual exceedance time series in Busan site and the average line of annual exceedance time series for each period. In Figure 12, "**" is the observed annual exceedance time series, and " $\bigcirc$ " is the annual exceedance time series in present and future climate conditions obtained from climate models. The solid line is the average of the annual exceedance time series in present and future climate conditions and the dotted line is the range of the standard 
deviation of the annual exceedance time series. As can be seen in Figure 12, the rate of change of annual exceedance time series is found to vary widely depending on which climate model is applied.
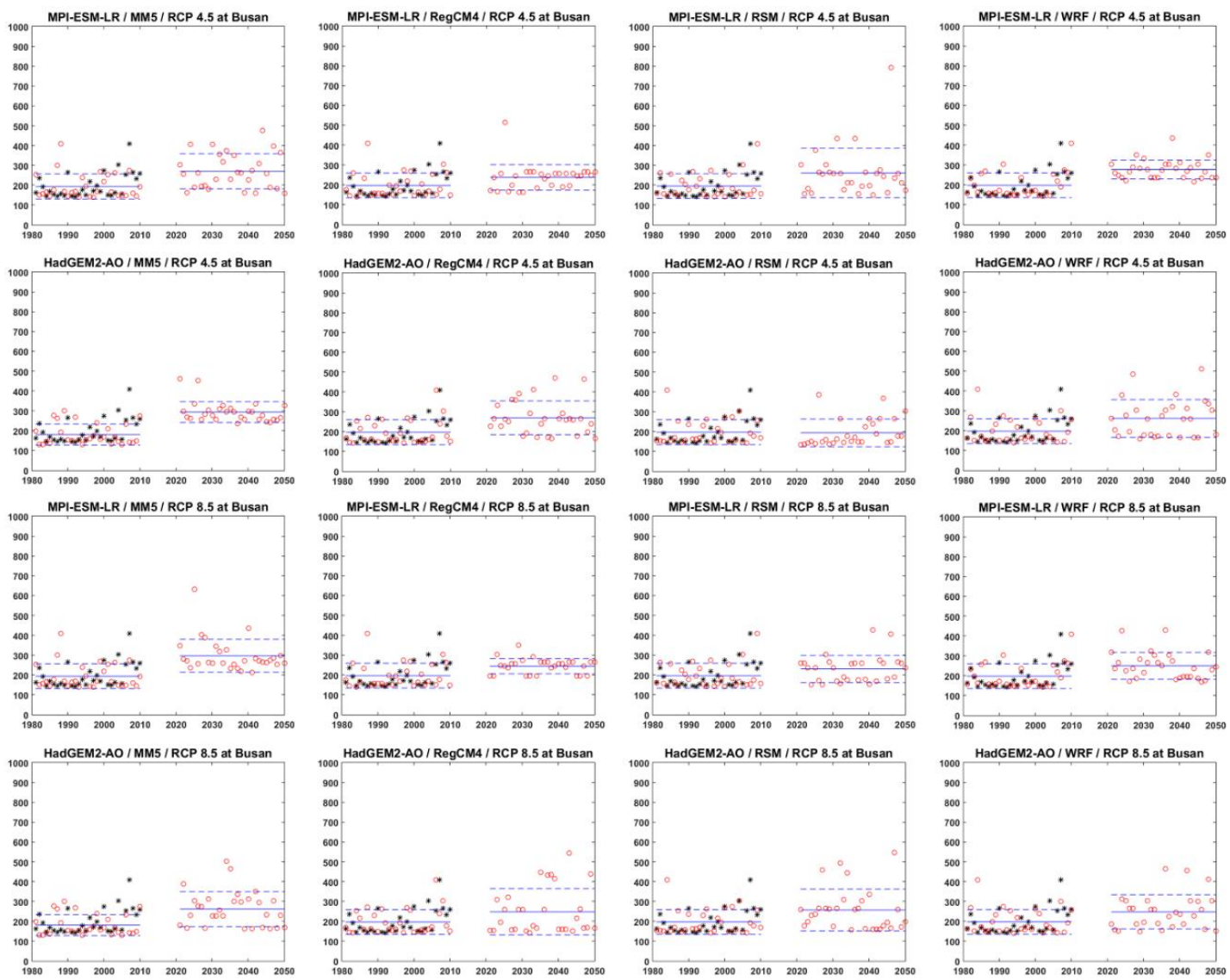

Figure 12. Annual exceedance daily rainfall depth of present and future at Busan site.

Figure 13 shows the box-plot of the future change rates of 16 annual exceedance time series for major sites. Unlike the rate of change of SAT and DPT shown in Figure 11, the rate of change of the annual exceedance time series is significantly different depending on which climate model is applied, and it is difficult to find the consistency of the rate of change by RCP scenarios. As mentioned above, the future extreme rainfall varies greatly depending on which climate model is applied, resulting in inconsistent future projection results. Therefore, it is considered to be one of the reasonable approaches to investigate the change of future extreme daily rainfall depth as a function of SAT or DPT to obtain consistent future projection results.

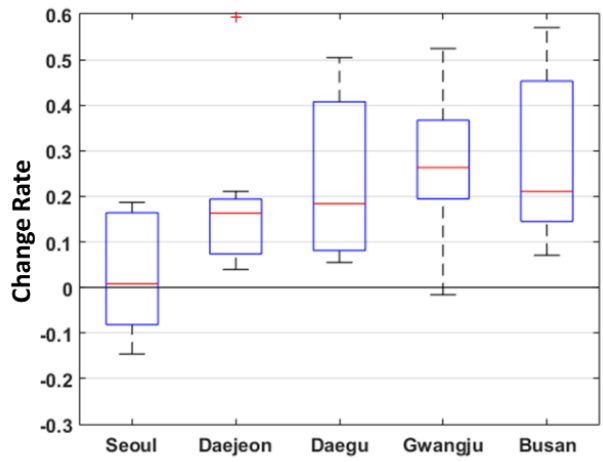

(a) SAT

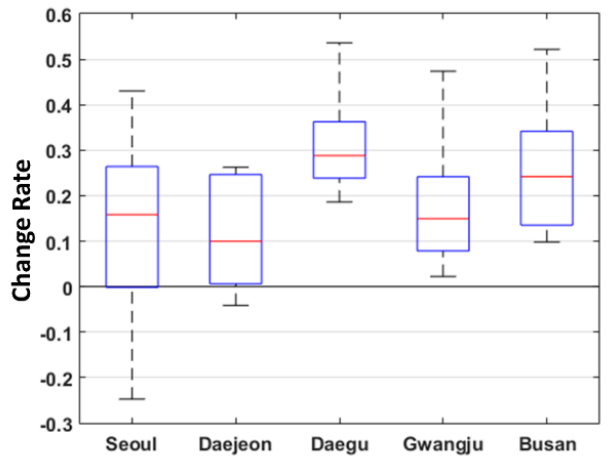

(b) DPT

Figure 13. Change rate of annual exceedance daily rainfall depth. 


\subsection{Sensitivity Analysis of Future Projection Data}

In this section, the relationship between the daily rainfall and the SAT/DPT of future data was explored in the same way as the analysis of observed data using a total of 16 future ensembles as described in Section 3.2. Figures 14 and 15 show the range of sensitivities of annual exceedance daily rainfall for SAT/DPT obtained using present and future climate simulation data. For reference, the leftmost box-plots in the figure were obtained as a result of observations using the sensitivity results in the applied 60 sites. Box-plots created using data from each climate model were obtained using the sensitivity results in the applied 60 sites.

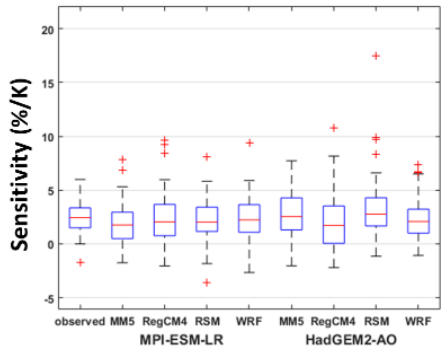

(a) Present

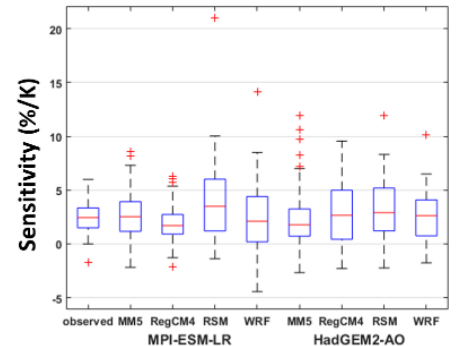

(b) RCP 4.5

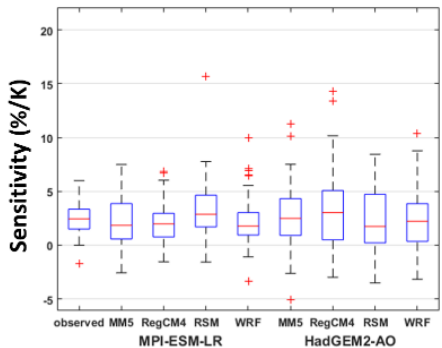

(c) RCP 8.5

Figure 14. Sensitivity of annual exceedance daily rainfall depth to SAT.

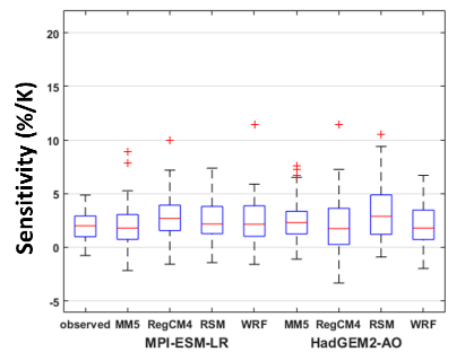

(a) Present

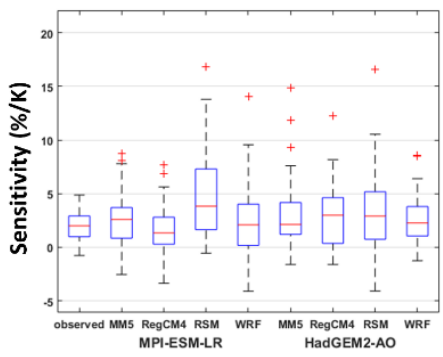

(b) RCP 4.5

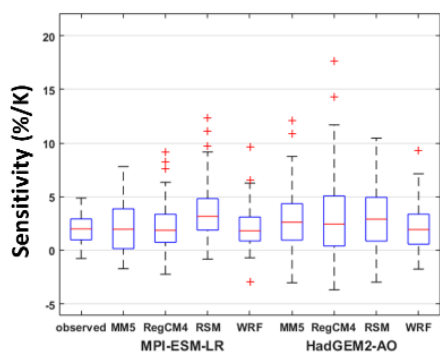

(c) RCP 8.5

Figure 15. Sensitivity of annual exceedance daily rainfall depth to DPT.

As can be seen in Figures 14 and 15, both SAT and DPT were found to be relatively well reproducible for the sensitivity obtained from the observational data. This means that analyzing future extreme daily rainfall depth using SAT and DPT data derived from climate models can be somewhat reliable.

Looking at the future rate of change in Section 3.2 above, it could be seen that the rate of change of SAT and DPT was more consistent than the rate of change of extreme rainfall. Therefore, rather than looking directly at future extreme rainfall changes by using the future rainfall data obtained from climate models, it was considered to be a more reliable approach to indirectly examine the future extreme rainfall behavior using the rate of change of future SAT and DPT.

Two approaches have been applied to examine the overall tendency of future extreme rainfall. Using the $d E_{\tau}(\% / K)$ obtained from the observations (see Equation (4)) and $\triangle S A T_{Y}$ (or $\triangle D P T_{Y}$ ) obtained from future data (see Equations (7) and (8)), the average rate of change of the annual exceedance daily rainfall depth was estimated. In addition, the rate of change of future annual exceedance daily rainfall time series was also estimated by directly using future rainfall data obtained from climate models using Equation (9). Figures 16 and 17 show the estimated rates of change in two ways. Figures 16a and 17a show the results of applying the RCP 4.5 scenario, and Figures $16 \mathrm{~b}$ and $17 \mathrm{~b}$ show the results of applying the RCP 8.5 scenario. The deviation between the ensemble is much smaller when estimating the rate of change of extreme rainfall using future SAT or DPT, rather than estimating the rate of change of extreme rainfall directly using future rainfall data. Also, the variability of the rate of change between sites was much lower when estimating the rate of change of extreme rainfall using the future 
SAT or DPT. The range of the ensemble average of the change rates by sites was $2.79-32.07 \%$ when the future rainfall data were directly used. In contrast, when SAT was used, it ranged from -3.10 to $10.04 \%$ (under RCP 4.5) and from -3.86 to $12.30 \%$ (under RCP 8.5). When DPT was used, it ranged from -1.31 to $8.29 \%$ (under RCP 4.5 ) and from -1.47 to $9.39 \%$ (under RCP 8.5 ). From these results, it would be more reasonable to examine the future extreme rainfall changes using future projection results of future SAT and DPT.

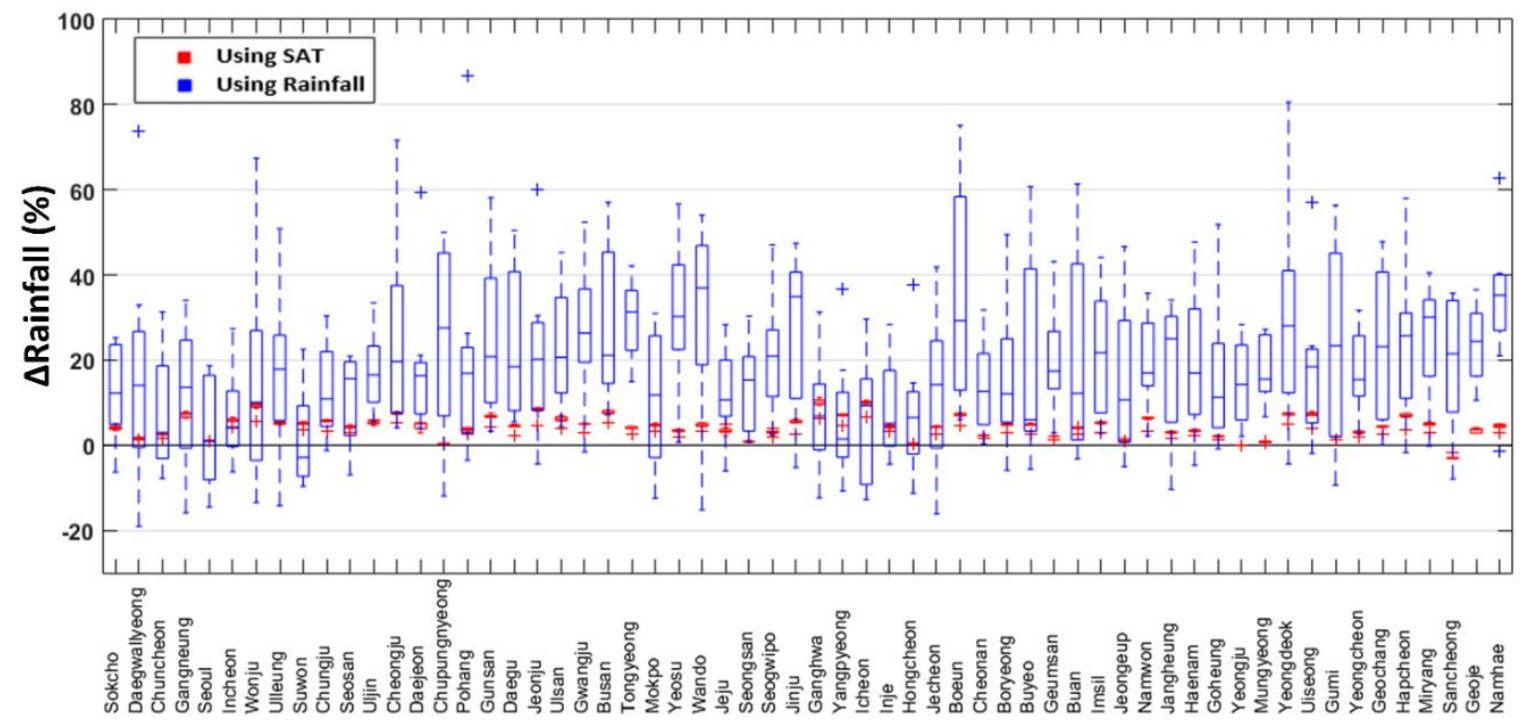

(a) RCP 4.5

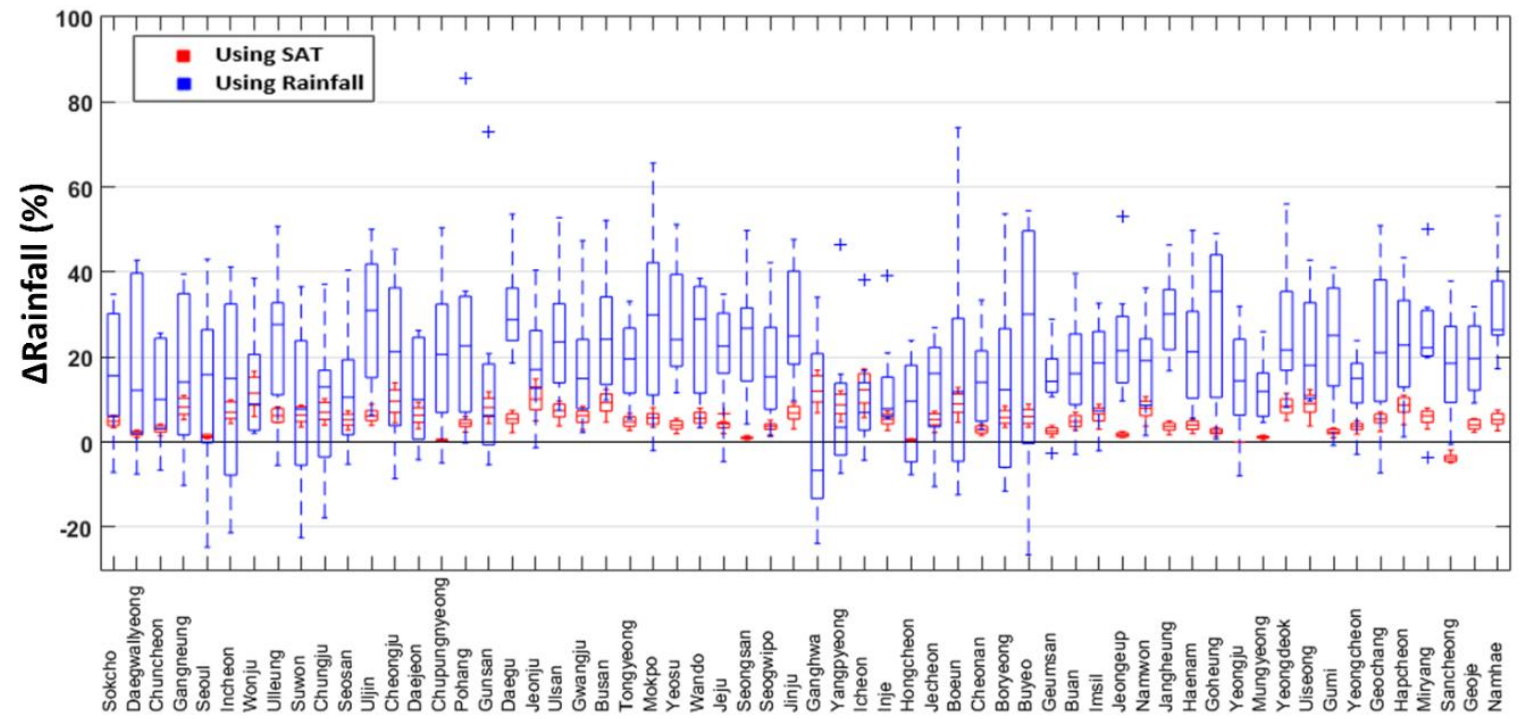

(b) RCP 8.5

Figure 16. Change rate of future annual exceedance daily rainfall depth using SAT and rainfall data. 


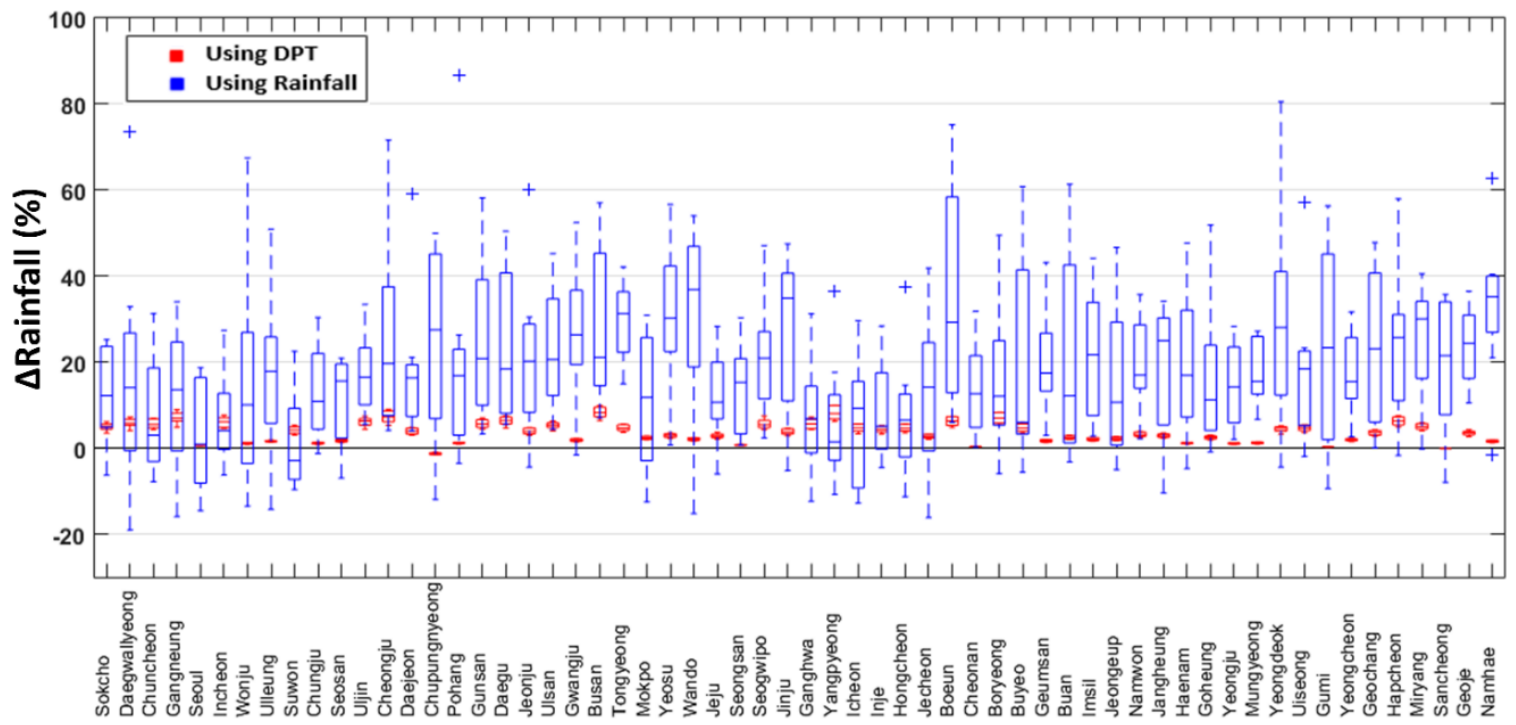

(a) RCP 4.5

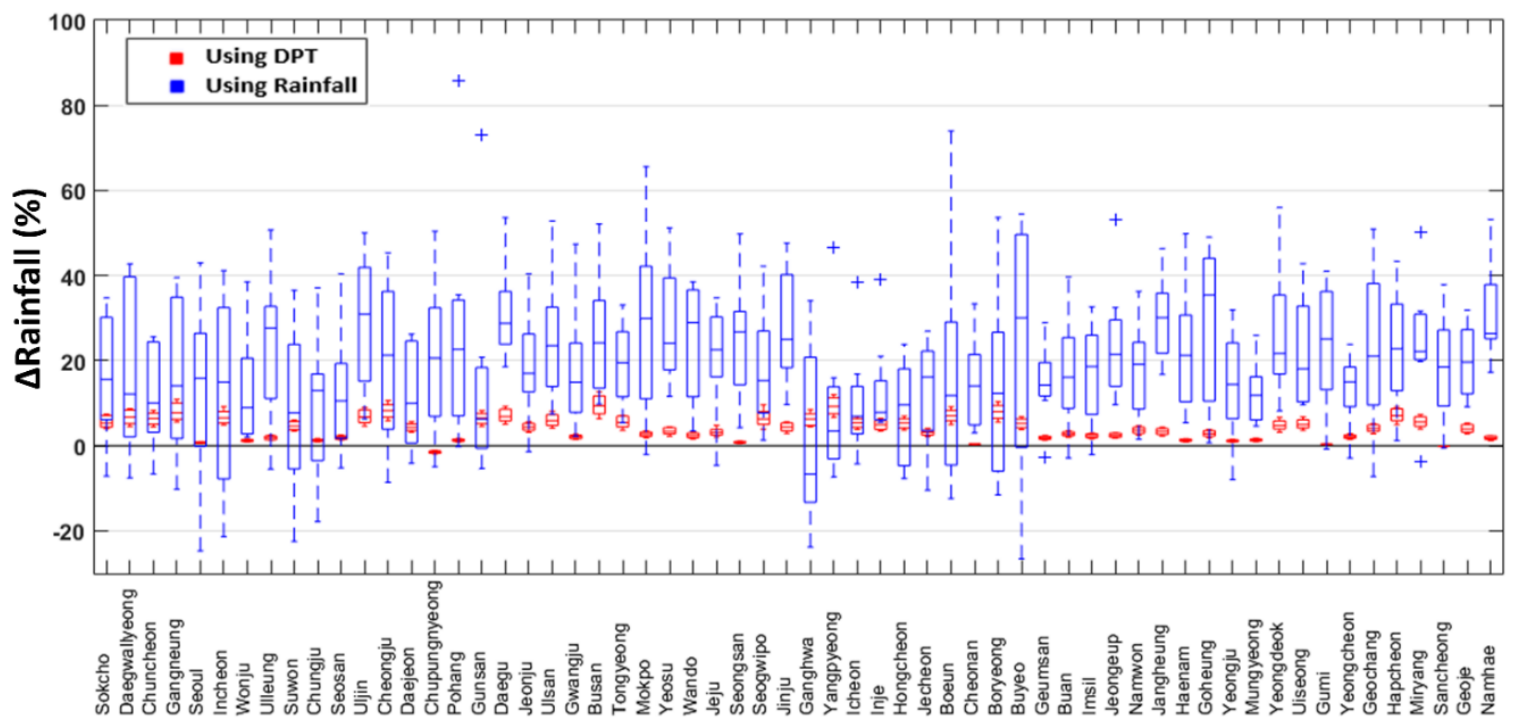

(b) RCP 8.5

Figure 17. Change rate of future annual exceedance daily rainfall depth using DPT and rainfall data.

As previously analyzed, the average change in future annual exceedance rainfall depth was found in two ways. The first is to extract an annual exceedance rainfall time series from simulated future rainfall data from various climate models and compare them with the corresponding present values. The second method is to investigate the future annual exceedance rainfall depth by linking the observed annual exceedance rainfall depth-SAT/DPT relationship with the future SAT/DPT information obtained from various climate models. The main difference between the first method and the second method lies in what data are used as future climate information. The first method directly estimates the annual exceedance rainfall depth using future rainfall data itself, while the second method indirectly estimates the annual exceedance rainfall depth using future SAT or DPT data. As mentioned earlier, most of the climate models one can use to obtain future climate information have limitations in implementing rainfall, especially extreme rainfall, and especially in the case of complex terrain such as the Korean Peninsula, such limitations become more prevalent. Therefore, very different extreme rainfall projections are likely to be produced depending on what climate model was applied and future rainfall data was obtained. In this study, there was a site to obtain a rate of change of -10 to $20 \%$ depending on which climate model was applied, and a site to obtain a rate of change of 0 to $60 \%$. Academically, various analyses of the ensemble of extreme rainfall obtained from 
various climate models would be possible and provide meaningful insights. However, it would not be advisable to suggest a future projection result that would vary greatly depending on what climate model was applied when it was to be used as a practical policy. On the other hand, when examining the future extreme rainfall changes using future SAT or DPT information obtained from various climate models, not only did one obtain relatively consistent projection results regardless of climate models, but also the rate of change was produced at a policy acceptable level. Therefore, looking at the future trend of extreme rainfall in this direction is expected to be a reasonable approach.

\section{Conclusions}

Climate change has increased the frequency and intensity of extreme rainfall, and the change in extreme rainfall has been socially and economically damaging and has received worldwide attention. The importance of predicting and analyzing future extreme rainfall is increasing, but the future rainfall data obtained from climate models includes many uncertainties. Since climate models simulate future SAT and DPT relatively consistently, it is believed that future reliable projection results can be obtained. On the other hand, future rainfall simulated from climate models is difficult to see as providing reliable future projection results, since different projection results are obtained for each model. Therefore, it may be a reasonable approach to look at the impact of extreme rainfall on climate change using meteorological variables such as SAT or DPT.

In this study, sensitivity analysis of extreme daily rainfall for SAT or DPT was performed using the data of $60 \mathrm{ASOS}$ sites operated by KMA. In most sites, the extreme daily rainfall depth and the SAT of the rainy day were negatively correlated, whereas DPT showed a positive correlation. However, considering the cooling effect when rainfall occurred, sensitivity analysis was performed by applying SAT/DPT up to 7 days including the day when rainfall was observed. As a result, extreme daily rainfall depth and SAT/DPT showed a positive correlation.

Sensitivity analysis was also performed in the same way as the analysis of observation data using future data obtained from climate models. As a result, it was confirmed that the sensitivity similar to the sensitivity found in the observation data was reproduced. Therefore, it can be concluded that there is no great difficulty in examining the sensitivity of future extreme rainfall using data obtained from climate models.

Using the data obtained from various climate models, the rate of change of future yearly SAT, future yearly DPT, and future annual exceedance daily rainfall depth was analyzed. When directly examining future extreme rainfall changes using the future rainfall data obtained from climate models, very different future projection results were derived depending on which climate model was applied. On the other hand, when indirectly looking at future changes in extreme rainfall using trends in future SAT or DPT data obtained from climate models and the sensitivity between SAT or DPT and extreme rainfall identified in observations, consistent projection results were obtained regardless of the climate model. Therefore, it could be a reasonable approach to look at the changes of future extreme rainfall using meteorological variables such as SAT or DPT.

Author Contributions: Conceptualization, I.S., O.L. and S.K.; Methodology, I.S. and S.K.; Software, I.S. and S.K.; Validation, I.S., O.L. and S.K.; Formal analysis, I.S.; Investigation, I.S.; Resources, S.K.; Data curation, I.S.; Writing-Original Draft Preparation, I.S.; Writing-Review and Editing, I.S., O.L. and S.K.; Visualization, I.S.; Supervision, S.K.; Project Administration, S.K.; Funding Acquisition, S.K.

Funding: This work is supported by the Korea Environmental Industry \& Technology Institute (KEITI) grant funded by the Ministry of Environment (RE201901073). The authors also acknowledge that this work was supported by the National Research Foundation of Korea (NRF) grant funded by the Korea government (MSIT) (No. NRF-2019R1A2C1003114).

Conflicts of Interest: The authors declare no conflict of interest. 


\section{References}

1. Rosenzweig, C.; Iglesias, A.; Yang, X.B.; Epstein, P.R.; Chivian, E. Climate change and extreme weather events; implications for food production, plant diseases, and pests. Glob. Chang. Hum. Health 2001, 2, 90-104. [CrossRef]

2. Luber, G.; McGeehin, M. Climate change and extreme heat events. Am. J. Prev. Med. 2008, 35, 429-435. [CrossRef]

3. Cox, P.M.; Betts, R.A.; Jones, C.D.; Spall, S.A.; Totterdell, I.J. Acceleration of global warming due to carbon-cycle feedbacks in a coupled climate model. Nature 2000, 408, 184-187. [CrossRef]

4. Groisman, P.Y.; Knight, R.W.; Easterling, D.R.; Karl, T.R.; Hegerl, G.C.; Razuvaev, V.N. Trends in intense precipitation in the climate record. J. Clim. 2005, 18, 1326-1350. [CrossRef]

5. Elsner, J.B.; Kossin, J.P.; Jagger, T.H. The increasing intensity of the strongest tropical cyclones. Nature 2008, 455, 92-95. [CrossRef]

6. Tsuboki, K.; Yoshioka, M.K.; Shinoda, T.; Kato, M.; Kanada, S.; Kitoh, A. Future increase of supertyphoon intensity associated with climate change. Geophys. Res. Lett. 2015, 42, 646-652. [CrossRef]

7. Bates, B.; Evans, J.; Green, J.; Griesser, A.; Jakob, D.; Lau, R.; Lehmann, E.; Leonard, M.; Phatak, A.; Rafter, T.; et al. Australian Rainfall and Runoff Revision Project 1: Development of Intensity-Frequency-Duration Information Across Australia; Engineers Australia, Water Engineering: Barton, Australia, 2015.

8. O'Gorman, P.A. Precipitation extremes under climate change. Curr. Clim. Chang. Rep. 2015, 1, 49-59. [CrossRef]

9. Coles, S.; Pericchi, L.R.; Sisson, S. A fully probabilistic approach to extreme rainfall modeling. J. Hydrol. 2003, 273, 35-50. [CrossRef]

10. Goswami, B.N.; Venugopal, V.; Sengupta, D.; Madhusoodanan, M.S.; Xavier, P.K. Increasing trend of extreme rain events over India in a warming environment. Science 2006, 314, 1442-1445. [CrossRef]

11. Guhathakurta, P.; Sreejith, O.P.; Menon, P.A. Impact of climate change on extreme rainfall events and flood risk in India. J. Earth Syst. Sci. 2011, 120, 359. [CrossRef]

12. Ávila, Á.; Guerrero, F.C.; Escobar, Y.C.; Justino, F. Recent precipitation trends and floods in the Colombian Andes. Water 2019, 11, 379. [CrossRef]

13. Utsumi, N.; Seto, S.; Kanae, S.; Maeda, E.E.; Oki, T. Does higher surface temperature intensify extreme precipitation? Geophys. Res. Lett. 2011, 38, L16708. [CrossRef]

14. Panthou, G.; Mailhot, A.; Laurence, E.; Talbot, G. Relationship between surface temperature and extreme rainfalls: A multi-time-scale and event-based analysis. J. Hydrometeorol. 2014, 15, 1999-2011. [CrossRef]

15. Wasko, C.; Sharma, A.; Johnson, F. Does storm duration modulate the extreme precipitation-temperature scaling relationship? Geophys. Res. Lett. 2015, 42, 8783-8790. [CrossRef]

16. Herath, S.M.; Sarukkalige, R.; Van Nguyen, V.T. Evaluation of empirical relationships between extreme rainfall and daily maximum temperature in Australia. J. Hydrol. 2018, 556, 1171-1181. [CrossRef]

17. Allen, M.R.; Ingram, W.J. Constraints on future changes in climate and the hydrologic cycle. Nature 2002, 419, 224. [CrossRef]

18. Min, S.K.; Zhang, X.; Zwiers, F.W.; Hegerl, G.C. Human contribution to more-intense precipitation extremes. Nature 2011, 470, 378. [CrossRef]

19. Fujita, M.; Mizuta, R.; Ishii, M.; Endo, H.; Sato, T.; Okada, Y.; Kawazoe, S.; Sugimoto, S.; Ishihara, K.; Watanabe, $\mathrm{S}$. Precipitation changes in a climate with $2-\mathrm{K}$ surface warming from large ensemble simulations using 60-km global and 20-km regional atmospheric models. Geophys. Res. Lett. 2019, 46, 435-442. [CrossRef]

20. Sachindra, D.A.; Ng, A.W.M.; Muthukumaran, S.; Perera, B.J.C. Impact of climate change on urban heat island effect and extreme temperatures: A case-study. Q. J. R. Meteorol. Soc. 2016, 142, 172-186. [CrossRef]

21. Crowley, T.J. Causes of climate change over the past 1000 years. Science 2000, 289, 270-277. [CrossRef]

22. IPCC. Managing the Risks of Extreme Events and Disasters to Advance Climate Change Adaptation. A Special Report of Working Groups I and II of the Intergovernmental Panel on Climate Change; Cambridge University Press: Cambridge, UK, 2012.

23. Hirabayashi, Y.; Kanae, S.; Emori, S.; Oki, T.; Kimoto, M. Global projections of changing risks of floods and droughts in a changing climate. Hydrol. Sci. J. 2008, 53, 754-772. [CrossRef]

24. Kawagoe, S.; Kazama, S.; Sarukkalige, P.R. Probabilistic modelling of rainfall induced landslide hazard assessment. Hydrol. Earth Syst. Sci. 2010, 14, 1047-1061. [CrossRef] 
25. Allan, R.P.; Soden, B.J. Atmospheric warming and the amplification of precipitation extremes. Science 2008, 321, 1481-1484. [CrossRef]

26. Westra, S.; Alexander, L.V.; Zwiers, F.W. Global increasing trends in annual maximum daily precipitation. J. Clim. 2013, 26, 3904-3918. [CrossRef]

27. Fischer, E.M.; Knutti, R. Anthropogenic contribution to global occurrence of heavy-precipitation and high-temperature extremes. Nat. Clim. Chang. 2015, 5, 560. [CrossRef]

28. Trenberth, K.E.; Dai, A.; Rasmussen, R.M.; Parsons, D.B. The changing character of precipitation. Bull. Am. Meteorol. Soc. 2003, 84, 1205-1218. [CrossRef]

29. Giorgi, F.; Raffaele, F.; Coppola, E. The response of precipitation characteristics to global warming from climate projections. Earth Syst. Dyn. 2019, 10, 73-89. [CrossRef]

30. O'Gorman, P.A.; Schneider, T. The physical basis for increases in precipitation extremes in simulations of 21st-century climate change. Proc. Nat. Acad. Sci. USA 2009, 106, 14773-14777. [CrossRef]

31. Johnson, F.; White, C.J.; van Dijk, A.; Ekstrom, M.; Evans, J.P.; Jakob, D.; Kiem, A.S.; Leonard, M.; Rouillard, A.; Westra, S. Natural hazards in Australia: Floods. Clim. Chang. 2016, 139, 21-35. [CrossRef]

32. Romps, D.M. Response of tropical precipitation to global warming. J. Atmos. Sci. 2011, 68, $123-138$. [CrossRef]

33. Bae, D.H.; Jung, I.W.; Lee, B.J.; Lee, M.H. Future Korean water resources projection considering uncertainty of GCMs and hydrological models. J. Korea Water Res. Assoc. 2011, 44, 389-406. [CrossRef]

34. Kim, K.; Lee, J.; Keum, J.; Park, M.; Kim, S. Uncertainty of future intensity-duration-frequency curves using multi-regional climate models. J. Korean Soc. Hazard Mitig. 2018, 18, 405-416. [CrossRef]

35. O'Gorman, P.A. Sensitivity of tropical precipitation extremes to climate change. Nat. Geosci. 2012, 5, 697-700. [CrossRef]

36. Tramblay, Y.; Neppel, L.; Carreau, J.; Najib, K. Non-stationary frequency analysis of heavy rainfall events in southern France. Hydrol. Sci. J. 2013, 58, 280-294. [CrossRef]

37. Chan, S.C.; Kendon, E.J.; Roberts, N.M.; Fowler, H.J.; Blenkinsop, S. Downturn in scaling of UK extreme rainfall with temperature for future hottest days. Nat. Geosci. 2016, 9, 24-28. [CrossRef]

38. Ivancic, T.J.; Shaw, S.B. A US-based analysis of the ability of the Clausius-Clapeyron relationship to explain changes in extreme rainfall with changing temperature. J. Geophys. Res. Atmos. 2016, 121, 3066-3078. [CrossRef]

39. Ali, H.; Mishra, V. Contrasting response of rainfall extremes to increase in surface air and dewpoint temperatures at urban locations in India. Sci. Rep. 2017, 7, 1228. [CrossRef] [PubMed]

40. Wasko, C.; Lu, W.T.; Mehrotra, R. Relationship of extreme precipitation, dry-bulb temperature, and dew point temperature across Australia. Environ. Res. Lett. 2018, 13, 074031. [CrossRef]

41. Kim, B.S.; Kim, B.K.; Kyung, M.S.; Kim, H.S. Impact assessment of climate change on extreme rainfall and IDF analysis. J. Korea Water Res. Assoc. 2008, 41, 379-394. [CrossRef]

42. Kim, K.Y.; Kim, B.S. Analysis of impact climate change on extreme rainfall using B2 climate change scenario and extreme indices. J. Korean Soc. Civ. Eng. 2009, 29, $23-33$.

43. Kwon, M.; Lee, G.; Jun, K.S. Analysis of annual maximum daily rainfall using RCP climate change scenario in Korean peninsula. J. Korean Soc. Hazard Mitig. 2015, 15, 99-110. [CrossRef]

44. Lenderink, G.; Mok, H.Y.; Lee, T.C.; Van Oldenborgh, G.J. Scaling and trends of hourly precipitation extremes in two different climate zones-Hong Kong and the Netherlands. Hydrol. Earth Syst. Sci. 2011, 15, 3033-3041. [CrossRef]

45. Yu, R.; Li, J. Hourly rainfall changes in response to surface air temperature over eastern contiguous China. J. Clim. 2012, 25, 6851-6861. [CrossRef]

46. Lenderink, G.; Van Meijgaard, E. Linking increases in hourly precipitation extremes to atmospheric temperature and moisture changes. Environ. Res. Lett. 2010, 5, 025208. [CrossRef]

47. Shaw, S.B.; Royem, A.A.; Riha, S.J. The relationship between extreme hourly precipitation and surface temperature in different hydroclimatic regions of the United States. J. Hydrometeorol. 2011, 12, 319-325. [CrossRef]

48. Berg, P.; Moseley, C.; Haerter, J.O. Strong increase in convective precipitation in response to higher temperatures. Nat. Geosci. 2013, 6, 181. [CrossRef]

49. Kwon, T.Y.; Oh, S.N.; Park, S.W. Long-term variability and regional characteristics of summer rainfall in Korea. J. Korean Meteorol. Soc. 1998, 34, 20-30. 
50. Choi, J.W.; Lee, J.S.; Moon, I.J. Second Changma retreat variability in Korea using the available water resources index and relevant large-scale atmospheric circulation. Int. J. Climatol. 2016, 36, 2273-2287. [CrossRef]

51. Choi, J.; Lee, O.; Jang, J.; Jang, S.; Kim, S. Future intensity-depth-frequency curves estimation in Korea under representative concentration pathway scenarios of Fifth assessment report using scale-invariance method. Int. J. Climatol. 2019, 39, 887-900. [CrossRef]

52. Kim, G.; Cha, D.H.; Park, C.; Lee, G.; Jin, C.S.; Lee, D.K.; Suh, M.S.; Ahn, J.B.; Min, S.K.; Hong, S.Y.; et al. Future changes in extreme precipitation indices over Korea. Int. J. Climatol. 2018, 38, e862-e874. [CrossRef]

53. The Daily ASOS Meteorological Data on the KMA Website. Available online: http://data.kma.go.kr (accessed on 12 April 2019).

54. Lepore, C.; Veneziano, D.; Molini, A. Temperature and CAPE dependence of rainfall extremes in the eastern United States. Geophys. Res. Lett. 2015, 42, 74-83. [CrossRef]

55. Boé, J.; Terray, L.; Habets, F.; Martin, E. Statistical and dynamical downscaling of the Seine basin climate for hydro-meteorological studies. Int. J. Climatol. J. R. Meteorol. Soc. 2007, 27, 1643-1655. [CrossRef]

56. Kim, E.; Choi, H.I.; Park, M.J.; Cho, S.J.; Kim, S. The effect of climate change on Korean drought occurrences using a stochastic soil water balance model. Sci. Res. Essays 2011, 6, 2771-2783.

57. Seo, L.; Jeon, M.; Kim, T.W.; Kim, S. Ensemble prediction of future design rainfalls considering climate change. J. Korean Soc. Hazard Mitig. 2012, 12, 159-172. [CrossRef]

58. Sim, H.J.; Ahn, M.; Kim, S. Feasibility assessment of RCP 8.5 in extreme air temperature. J. Korean Soc. Hazard Mitig. 2014, 14, 351. [CrossRef]

59. Lee, A.; Cho, S.; Kang, D.K.; Kim, S. Analysis of the effect of climate change on the Nakdong river stream flow using indicators of hydrological alteration. J. Hydroenviron. Res. 2014, 8, 234-247. [CrossRef]

60. Choi, J.; Lee, O.; Kim, S. Analysis of the effect of climate change on IDF curves using scale-invariance technique: Focus on RCP 8.5. J. Korea Water Res. Assoc. 2016, 49, 995-1006. [CrossRef]

61. Lee, O.; Jo, D.J.; Kim, S. Future PMP estimation of Chungjudam watershed under KMA climate change scenarios. J. Korean Soc. Hazard Mitig. 2017, 17, 365-373. [CrossRef]

62. Cha, W.; Lee, O.; Kim, S.; Park, Y. Analysis of indicators of hydrological alteration on the Geumho river basin under AR5 RCP scenarios. J. Korean Soc. Hazard Mitig. 2017, 17, 317-326. [CrossRef]

63. Lee, O.; Jang, J.; Park, M.J.; Lee, Y.; Kim, S. Estimation of PMP in nuclear power plants area considering climate change. J. Korean Soc. Hazard Mitig. 2017, 17, 549-557. [CrossRef]

64. Cha, W.; Lee, O.; Choi, J.; Lee, J.; Kim, S. Future hourly rainfall data production using point rainfall model and future stormwater analysis. J. Korean Soc. Hazard Mitig. 2018, 18, 483-492. [CrossRef]

65. Lee, O.; Kim, S. Estimation of future probable maximum precipitation in Korea using multiple regional climate models. Water 2018, 10, 637. [CrossRef]

(C) 2019 by the authors. Licensee MDPI, Basel, Switzerland. This article is an open access article distributed under the terms and conditions of the Creative Commons Attribution (CC BY) license (http://creativecommons.org/licenses/by/4.0/). 